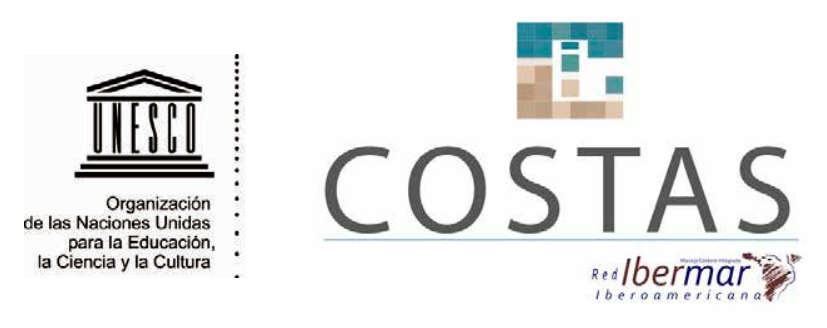

Iturralde M. G., M. Vera H., J.Coronel Q., 2021 Opportunities to Implement the Marine and Coastal Spatial Planning in Ecuador, a Case Study in the Northern coast of Manabí Province. Revista Costas, vol. esp., 2: 357-406. doi: 10.26359/costas.e1721

Scientific Article / Artigo Científico / Artículo Científico

Oportunidades para Implementar el Ordenamiento Espacial Marino y Costero en el Ecuador, un caso de Estudio en la Zona Costera Norte de la Provincia de Manabí

\title{
Opportunities to implement the Marine and Coastal Spatial Planning in Ecuador, a Case Study in the Northern Coast of Manabí Province
}

\author{
${ }^{1}$ Consultor independiente \\ ${ }^{2}$ Universidad Agraria del Ecuador,
}

Submitted: October 2020

Accepted: March 2021

Associate Editor: Eduardo Martins

\section{Gustavo Iturralde M. ${ }^{1}$, Mayra Vera H. ${ }^{1}$, Jorge Coronel Q. ${ }^{2}$}

e-mail: gustavo.yturralde@gmail.com

\author{
Keywords: Maritime Uses, Marine Planning, Local \\ Conflicts, Methodology, Pilot Project, Coastal \\ Planning.
}




\section{COSTAS}

Revista Costas, Vol. Esp. 2, 2021

rine and coastal management and ordering process due to their perception indicating that the rules are not being met and the existence of several conflicts, mainly between industrial and small-scale (artisanal) fishing. From the beginning of the project, we worked together with the local coastal communities, and the application of spatial analysis tools and remote sensors that served to alleviate the scarcity of available information. A methodology was then presented to assess the pre-feasibility of the area, with the aim to define how feasible, it is to carry out the process of planning marine and coastal uses. Once the viability was analyzed, three future management scenarios are proposed along with recommendations for the management of the area and the lessons learned. The study area has a high pre-feasibility to begin a process de marine and coastal planning due to the support of the local communities and the limited conflicts. Thus, it is recommended that this type of process should be promoted by the environmental authority by engaging and empowering resource users, before the conflicts are exacerbated and the communities and local governments lose interest due to lack of institutional support.

\section{Resumen}

En el 2018, el Ministerio del Ambiente y Agua con el apoyo de la Agencia de Cooperación Internacional Alemana (Gesellschaft für Internationale Zusammenarbeit GIZ) se evaluó la posibilidad de realizar un proceso de ordenamiento espacial marino y costero en la zona del norte de la provincia de Manabí, Ecuador; a través de talleres y entrevistas en territorio se identificó las principales cuestiones relativas al manejo en la zona costera, se determinó cuáles son los principales usos en el área (i.e., pesca artesanal, conservación, pesca industrial y turismo), así como los conflictos entre los usuarios. Las comunidades locales manifestaron su deseo de iniciar un proceso de ordenamiento debido a que es su percepción de que no se cumplen las normas y existen varios conflictos principalmente entre la pesca industrial y artesanal. Se trabajó desde el inicio del proyecto junto con las comunidades locales, en conjunto con el uso de herramientas de análisis espacial y sensores remotos que sirvió para paliar la escasez de información disponible. Como resultado, se presenta una metodología para evaluar la prefactibilidad del área, con la finalidad de establecer preliminarmente qué tan factible es llevar a cabo el proceso de ordenamiento de los usos marinos y costeros. Una vez analizada la viabilidad en el área, se proponen tres escenarios de manejo futuro, recomendaciones para el manejo del área y las lecciones aprendidas. La zona de estudio tiene una alta prefactibilidad para iniciar un proceso de ordenamiento marino y costero debido al apoyo de las comunidades locales y lo limitado de los conflictos, por lo que se recomienda que se impulse este tipo de procesos por parte de la autoridad ambiental, antes de que los conflictos se exacerben y las comunidades y gobiernos locales pierdan el interés por falta de apoyo institucional.

Palabras clave: Usos marítimos, Planificación marina, conflictos locales, metodología, proyecto piloto.

\section{Introducción}

Los servicios que proveen los océanos a la humanidad son muy importantes. Cerca de 3 mil millones de personas obtienen casi el $20 \%$ de su proteína animal de los peces, y la mayoría del pescado del mundo proviene del océano, casi la mitad de la proteína animal que se consume proviene de los peces (WWF, 2015). Cada vez más se reconoce la importancia de los ambientes marinos para la economía de los países y el desarrollo social de las comunidades de las cuales dependen. Se ha estimado que los océanos del plane- ta tienen un valor de 24 billones de dólares (WWF, 2015) lo que indica que si los océanos fueran un país serían la séptima economía en el mundo.

El Ecuador es un país con una alta vocación marítima que cuenta con posición privilegiada en la cuenca del Pacífico sudeste por su ubicación geoestratégica lo que le permite aspirar como posicionarse como la puerta de acceso logístico y comercial marítimo y aéreo del otro lado del océano Pacífico (Setemar, 2014); razón por lo cual es de gran importancia social, eco- 


\section{restis \\ COSTAS}

nómica y ambiental, en términos de transporte de carga, pesquerías y mantener los medios de vida de las comunidades costeras que dependen de sus servicios ambientales.

El Gobierno de Ecuador ha emprendido importantes iniciativas para la conservación de su capital natural; desde la Constitución de la República del Ecuador (Gobierno del Ecuador, 2008), se establecen los derechos de la naturaleza y se determina como prioridad la conservación, manejo y uso sostenible de los ecosistemas frágiles, especialmente los marino y costeros, mientras que el objetivo número tres del Plan Nacional de Desarrollo (Senplades, 2017) está enfocado a garantizar los derechos de la naturaleza para las actuales y futuras generaciones, abordando nueve políticas nacionales que son la base de las herramientas de conservación y uso sostenible de la biodiversidad.

Adicionalmente, Ecuador también cuenta, desde el 2014, con nueve políticas oceánicas costeras vigentes, y el Plan de Ordenamiento del Espacio Marino y Costero (Senplades, 2018), aprobado mediante el Comité Interinstitucional del Mar, en marzo del 2018, en el que se establecen ciertos lineamientos nacionales para la aplicación de las políticas oceánicas costeras en el desarrollo de la planificación de la zona marino-costera.

Sin embargo, en la práctica, la planificación en el medio marino es incipiente, ya que no existe un ordenamiento de los usos y actividades que se desarrollan tanto en la zona costera como marina más allá de los intereses sectoriales (por ejemplo pesquería, áreas protegidas, turismo, energía y transporte marítimo) que, en algunos casos, son contradictorios entre sí por lo que se afectan los ecosistemas, las especies y por consiguiente a las poblaciones humanas que dependen de los servicios ambientales de los cuales dependen. De no existir estrategias adecuadas de planificación, ordenamiento, gestión y conservación marina y costera, las actividades humanas tendrán un impacto negativo sobre la biodiversidad marina.

No obstante, hay que mencionar que, en los últimos ańos en el Ecuador, los diferentes procesos de planificación de las áreas marino costeras protegidas constituyen procesos participativos con lineamientos similares a la planificación espacial marina, aplicado a una escala local. Por otro lado, el trabajo del Programa de Manejo de Recursos Costeros (PMRC), desde sus inicios en la década de los 80 se enfocó en el ordenamiento de los usos marino - costeros y llegó incluso a una macro-zonificación en el año 2000 (PMRC, 2000) pero que no fue implementada porque no se dispuso de una autoridad con el mandato y los recursos necesarios para su implementación.

En el Ecuador, en julio del 2018, se realizó un taller de expertos y técnicos de las instituciones nacionales con competencia en el medio marino, durante el cual se propuso que el ordenamiento marino y costero: (i) sea considerado como "el proceso, participativo, adaptativo, basado en ciencia y que considera la dimensión espacial y temporal, mediante el cual las autoridades competentes planifican y coordinan los usos en los espacios marinos y costeros con el fin de alcanzar el desarrollo sostenible"; y (ii) se lo denomine como "Ordenamiento Espacial Marino y Costero (OEMC)", ya que se lo consideró como un paso más allá, puesto que incluye planificación más implementación (WWF, 2018).

La Planificación espacial marina (u el "ordenamiento espacial marino" como se comenzó a llamar en Ecuador) es un proceso que debe de ser considerado como un marco para la gobernanza integral y estar relacionado con un esquema aún mayor que incluye la política nacional, la planificación y el manejo de los usos y espacios marinos (Greenhill, 2018). El OEMC debe considerar un amplio espectro de actividades, normas y regulaciones para el uso adecuado del espacio marino permitiendo la sinergia de usos complementarios y separando usos incompatibles tanto espacial como temporalmente. 


\section{ri: COSTAS}

Según la legislación ecuatoriana los espacios marino y costeros se dividen zona costera y espacios marítimos en base a lo establecido por la Convención del Derecho del Mar (Convemar), cada uno de estos espacios define las competencias ya sean locales o nacionales (figura 1), pero también hay que considerar que hay competencias geográficas (por territorio: gobiernos cantonales y provinciales) y sectoriales (por actividad: pesca, acuacultura y turismo), en muchos casos las competencias sectoriales se intersecan entre sí (WWF, 2018), o con otros niveles de gobierno (nacional y local) lo que produce conflictos entre usuarios, sobreexplotación de los recursos naturales y superposición de competencias (WWF, 2018).

Es importante destacar que la zona de Manabí Norte tiene varias autoridades, con sus respectivas competencias que intervienen en un mismo territorio o ámbito geográfico y sobre los usos o actividades que sobre él se desarrollan. Así, en la zona costera, especialmente en las playas, los municipios tienen competencia plena sobre la administración del territorio, pero las autoridades sectoriales también tienen intereses sobre las diferentes actividades que se realizan en la misma (principalmente pesquerías, turismo, transporte). En cambio, en el área marina, las autoridades nacionales son las competentes, tales como la autoridad marítima, la autoridad pesquera, la autoridad acuícola, la autoridad ambiental y la autoridad de turismo, que, aunque administran diferentes actividades, ocupan el mismo espacio geográfico; por lo que desafortunadamente, esto ha fomentado la conflictividad en la zona, predominando la visión sectorial y no una integral, que una todos los intereses en una meta común orientada al desarrollo sustentable y equitativo en el área. En síntesis, un adecuado mapeo de actores sociales permite, desde el inicio, tener claridad sobre quiénes son los tomadores de decisiones - alto nivel de poder y sus intereses están a favor -; los cuales son fundamentales en los procesos de construcción, socialización y comunicación, quiénes aportan el conocimiento científico / empírico; así como quienes no cumplen ningún role en el OEM.

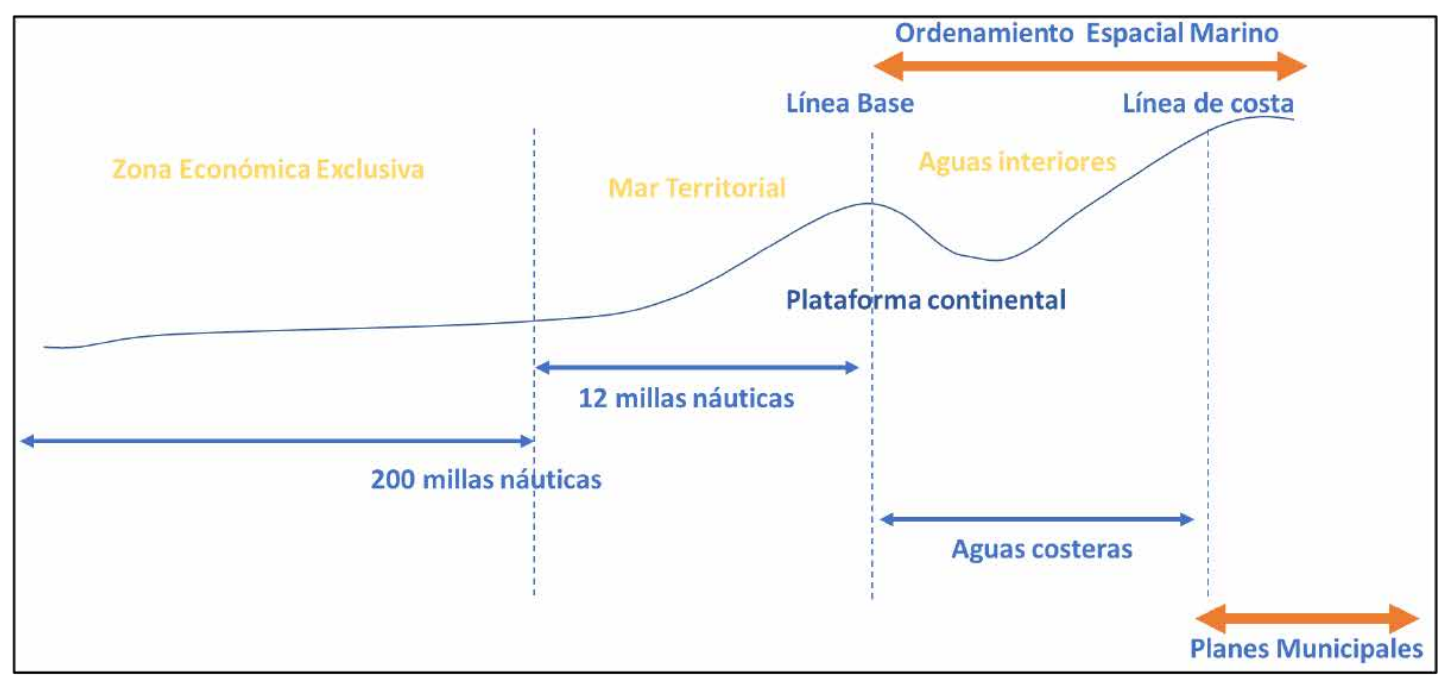

Figura 1. Espacios marinos en el área de estudio. Fuente: elaboración propia basado en Veidemane et al. (2017). Figure 1. Marine spaces in the study area. Source: own elaboration based on Veidemane et al. (2017). 


\section{re \\ COSTAS}

$\mathrm{Al}$ respecto, con el fin de atender esta problemática en la zona Norte de Manabí y obtener aprendizajes al respecto, en 2018, con el apoyo de la agencia de Cooperación Alemana (GIZ) y el Ministerio del Ambiente y Agua del Ecuador (MAAE), se realizaron tres consultorías para analizar la posibilidad de implementar un proceso de ordenamiento espacial marino (OEM) con enfoque ecosistémico en el área de estudio propuesta, que responda a un proceso participativo integrando a los diversos actores de la zona y los lineamientos nacionales de planificación y gestión marino costera, que tuvieron como finalidad 1) identificar si es posible o no implementar un proceso de ordenamiento del espacio marino en esta zona, 2) realizar un diagnóstico de los principales usos y conflictos identificados en el área, y 3 ) recomendaciones para su implementación; para el efecto se realizaron 3 consultorías: aspectos sociales (Vera, 2018), Cartografía (Coronel, 2018) y Planificación (Iturralde, 2018) donde se encuentra información más detallada sobre este proceso. El presente artículo resume las metodologías, procesos, metodologías y resultados de dichos estudios, con el fin presentar los fundamentos y experiencias obtenidas para el desarrollo e implementación de un OEM participativo, basado en la realidad del territorio y sus actores principales.

\section{Metodología}

\section{Área de estudio}

El área de estudio cubre la zona marina y costera desde el Estuario del Río Muisne, hasta el estuario del Río Chone, incluye una franja terrestre variable de zona costera desde un kilómetro hasta los límites del Refugio de Vida Silvestre Manglares del estuario del Río Muisne, y en la zona marina incluye las aguas interiores en un rango variable entre las 14 millas náuticas $(\mathrm{mn})$ al norte y las $20 \mathrm{mn}$ al sur del área (Figura 2) con una superficie total de $3518 \mathrm{~km}^{2}$ de las
En este contexto, los sensores remotos nos pueden brindar información oceanográfica actual y de alta resolución especialmente en temas de productividad primaria, temperatura superficial del mar, salinidad, corrientes, sobre todo lo relacionado con productividad primaria. Las técnicas de recolección y análisis de información, así como las fuentes de información son muchas y variadas. Entre ellas: Información científica académica publicada en revistas científicas, informes de investigación, información colectada por los que gestionan el sitio, panel de expertos, diagnósticos de varios tipos, análisis de fotografías aéreas orto rectificadas e imágenes satelitales, mapas parlantes o cartografía participativa y hasta grupos focales.

Bajo este marco de trabajo, este estudio evalúa una metodología inédita con escenarios para analizar la prefactibilidad de implementación el ordenamiento espacial marino y costero en el Ecuador, enfocado en la costa norte de la Provincia de Manabí (Ecuador) con la finalidad de definir qué tan factible es desarrollar un proceso de ordenamiento de los usos de recursos marinos y costeros en consenso y con el apoyo de las comunidades costeras.

cuales $3335 \mathrm{~km}^{2}$ son marinas y $183 \mathrm{~km}^{2}$ son terrestres. También representa un frente costero de 114.41 $\mathrm{km}$ en línea recta. El área abarca tres cantones del norte de la provincia de Manabí: Pedernales, Jama y San Vicente.

El área, según Ayón (1988), consta de una serie de anchos cordones litorales y acantilados antiguos. Los acantilados son interrumpidos por algunos valles fluviales. Los ríos aportan mucho sedimento durante la temporada de lluvias y en sus márgenes se desarro- 


\section{酯 \\ COSTAS}

llan terrazas planas, islas y lagunas costeras. Algunos salientes y playas embolsadas son de una belleza excepcional, pero inaccesibles desde tierra.

Para efectos de este trabajo y considerando los espacios marinos del Ecuador, tal y como son establecidos por la Convemar, el alcance de intervención incluye la zona de aguas interiores de la zona de estudio hasta la línea de más alta marea y adicionalmente en la zona costera adyacente, se incluye una franja terrestre de un ancho variable de mínimo un kilómetro.

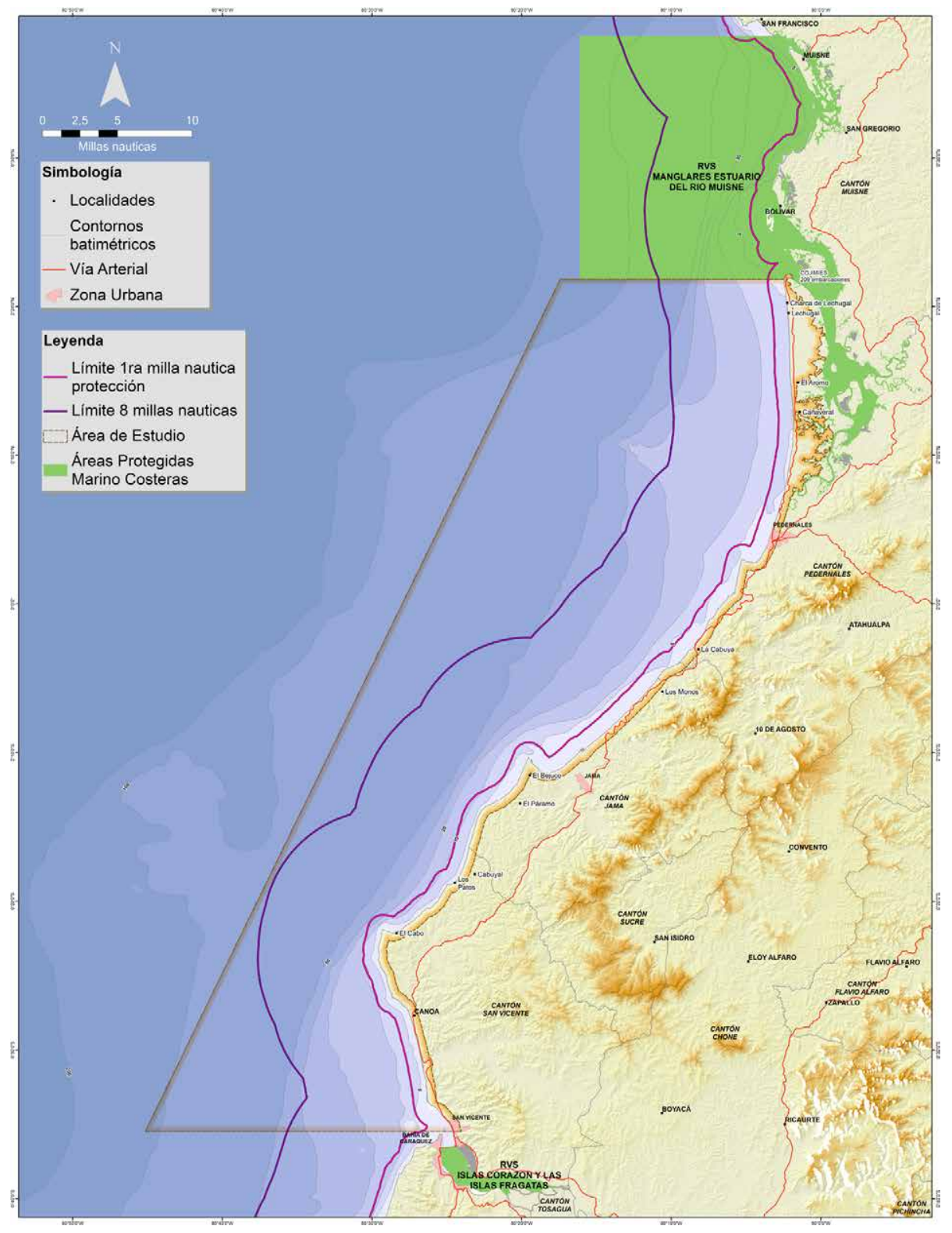

Figura 2. Mapa base del área de estudio, incluyendo el Estuario del Río Muisne hasta el estuario del Río Chone. Figure 2. Base map of the study area, from the Muisne River Estuary to the Chone River Estuary. 
La zona de estudio fue seleccionada previamente de forma conjunta entre el Ministerio del Ambiente y Agua, y la GIZ

\section{Descripción Socioeconómica}

El área estudiada presenta una población estimada al 2020 de 114336 habitantes (INEC, 2010a), con un índice de pobreza por necesidades básicas insatisfechas entre 85.6 a $93.7 \%$, los tres cantones tienen índice de pobreza mayores que el valor de la provincia (76.8 \%) y mayores que el índice nacional (60.1\%) (INEC, 2010b). Aunque hasta 1992 estos cantones pertenecían al Cantón Sucre y se fueron disgregando a medida de sus propias dinámicas políticas y sociales se pueden seguir considerando como un territorio marino y costero muy uniforme con las mismas potencialidades y desafíos.

En la provincia de Manabí la tasa de empleo pleno y subempleo es $56.9 \%$ apenas inferior del valor nacional (57.8 \%) (INEC, 2018), y en el área de estudio entre el $34.7 \%$ y el $59.6 \%$ se dedican a las actividades del sector primario como la agricultura, ganadería, silvicultura y pesca, en base a esto la falta de empleo adecuado es una problemática que presiona el uso de los recursos vivos, considerando que las actividades más importantes en la zona tienen que ver directamente con la agricultura, pesca y acuicultura (Gobierno Autónomo Descentralizado Cantonal (GADC) San Vicente, 2015; GADC Pedernales, 2015; GADC Jama, 2015).

\section{Breve reseña histórica}

El desarrollo de la zona norte de Manabí se puede definir en 4 etapas (tabla 1, figura 3. actualizado en base a PRMC, 1993), lo que nos indica que, aunque es una zona muy productiva, la falta de vías de acceso y los desastres naturales que han acontecido en la zona han afectado la economía y el desarrollo de la zona que vivió un boom turístico y acuícola en la década de los noventa.

\section{Herramientas para la planificación espacial marina}

El proceso se basó en el documento: "Guía Metodológica para el ordenamiento espacial marino en Costa Rica" cuyo objetivo es "Disponer de un instrumen-

Tabla 1. Etapas de desarrollo de la zona de Manabí Norte. Fuente: adaptado y actualizado de PMRC (1993). Table 1. Development stages of the Manabí Norte area. Source: adapted and updated from PMRC (1993).

\begin{tabular}{|l|l|l|}
\hline \multicolumn{1}{|c|}{ Período } & \multicolumn{1}{|c|}{ Tiempo } & \multicolumn{1}{c|}{ Descripción } \\
\hline Agrícola & Hasta 50s & $\begin{array}{l}\text { Desde la colonia, Bahía de Caráquez fue utilizada como puerto marítimo. Su calidad de } \\
\text { puerto y la construcción del ferrocarril en 1914 (el mismo que efectuaba un recorrido de 90 } \\
\text { km: Bahía-Tosagua-Estancilla-Calceta Canuto-Chone) le permitieron desarrollarse como un } \\
\text { destacado centro de exportación de productos agrícolas. }\end{array}$ \\
\hline Recesivo & Hasta 70s & $\begin{array}{l}\text { La construcción del puerto de Manta y de las carreteras produjeron un colapso en las activi- } \\
\text { dades portuarias de Bahía. }\end{array}$ \\
\hline Camaronero & Hasta 90s & $\begin{array}{l}\text { Se inició la construcción de piscinas camaroneras, primero en áreas salinas y luego en zonas } \\
\text { de manglar. El cultivo del camarón, en conjunto con el turismo y la bonanza petrolera nacio- } \\
\text { nal, reactivaron la economía local. } \\
\text { Ampliación del aeropuerto. }\end{array}$ \\
\hline Recesivo 2 & $\begin{array}{l}\text { Hasta la } \\
\text { actualidad }\end{array}$ & $\begin{array}{l}\text { Terremotos, Mancha blanca alejaron la inversión que se estaba recuperando hasta el nuevo } \\
\text { terremoto, Construcción de Puente "Los Caras", se rehabilita la carretera, pero no se espera } \\
\text { que se reabra el Aeropuerto Los Perales. Construcción de Facilidad Pesquera en Cojimíes. }\end{array}$ \\
\hline
\end{tabular}




\section{COSTAS}

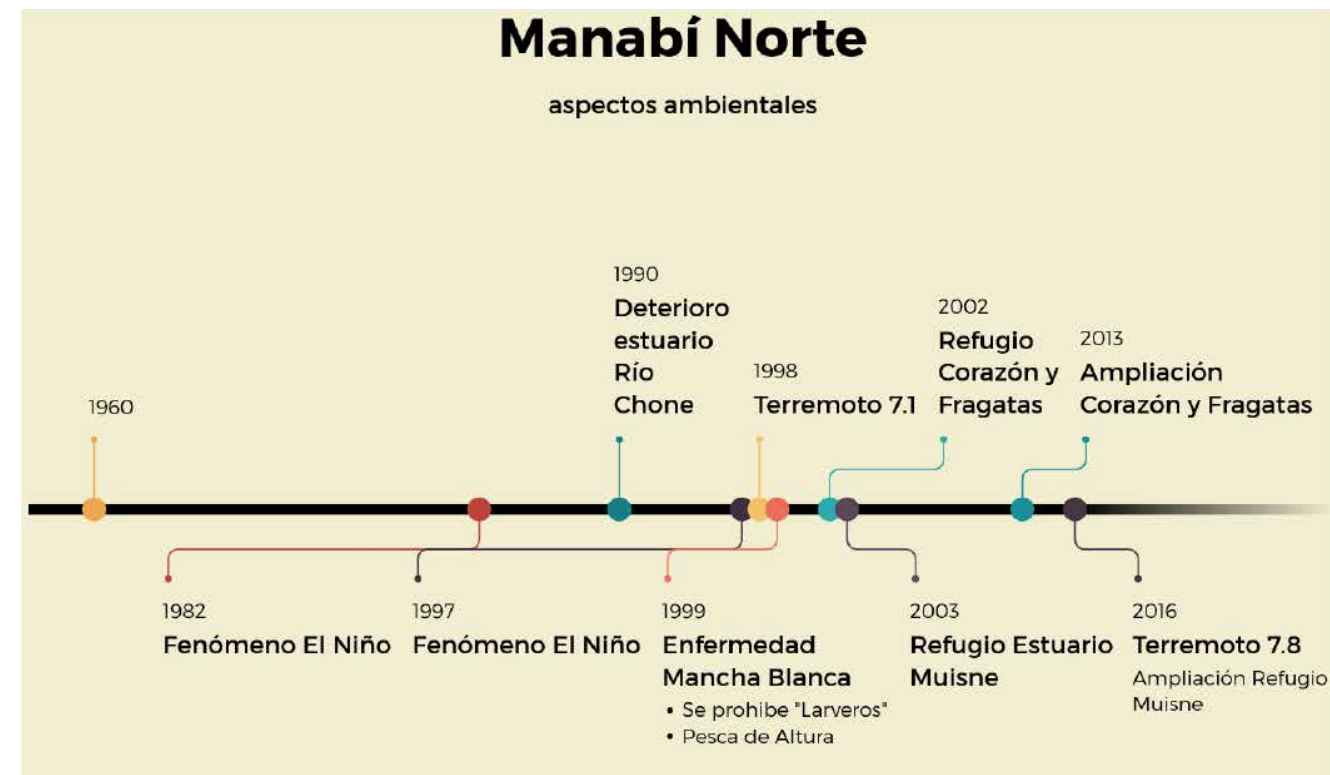

Figura 3. Hitos recientes en los aspectos ambientales en la zona de Manabí Norte. Fuente: elaboración propia.

Figure 3. Recent milestones in environmental aspects in the Manabí Norte area. Source: own elaboration.

to de planificación integral que dirija los procesos de OEM para gestionar el uso y aprovechamiento sostenible de los recursos marinos costeros en Costa Rica”, la cual ya está siendo utilizada en Ecuador por la Agencia de Cooperación Alemana en Esmeraldas, Ayangue, y, El Oro a través de talleres con actores locales y las autoridades competentes.

Este proceso tiene 8 etapas, que se detallan a continuación, pero en esta ocasión, por ser una prefactibilidad, el alcance de la misma solo incluyó hasta la etapa 4, Construcción participativa (figura 4).

\section{Definición de actores}

En base al trabajo de campo y la revisión de bibliografía se identificó a los actores principales dentro del área de estudio. Esta información fue complementada mediante entrevistas y talleres, donde se definió su interés hacia el proceso de ordenamiento del espacio marino y su relación de influencia hacia otros actores.

En el proceso de trabajo de identificación de actores, se promueve un acercamiento inicial con los involucrados a diferentes niveles. Ello para trasparentar, desde el inicio del proceso, el establecimiento de relaciones con los interesados, que es prerrequisito base para el OEM. A partir de este primer contacto se plantean y mapean las necesidades particulares para conformar los grupos de sectores. Se deberá caracterizar a los actores sociales con sus responsabilidades, expectativas, intereses, posiciones, experiencias y percepciones acerca del ordenamiento espacial marino.

\section{Recopilación de la información referente al sitio}

A partir de la definición del sitio a planificar y de la definición de actores interactuando en el espacio marino escogido, se procedió a realizar una recopilación y análisis de la información bibliográfica y espacial existente. Lo óptimo es disponer de información generada mediante la investigación académica-científica. Sin embargo, esto no siempre fue posible. En este sentido, se recomendó y se optó basarse en el conocimiento local y tradicional, sobre biodiversidad 
Iturralde, Vera \& Coronel

\begin{tabular}{|c|c|c|}
\hline \multirow[t]{13}{*}{ OEM } & \multirow[t]{2}{*}{ 1. Definición del Sitio a Planificar } & Criterios para la selección de un sitio a planificar \\
\hline & & Análisis de viabilidad \\
\hline & \multirow{2}{*}{ 2. Definición de actores } & Ente Rector \\
\hline & & Identificación de conflictos \\
\hline & \multirow{2}{*}{$\begin{array}{l}\text { 3. Disposición De Información Del } \\
\text { Sitio }\end{array}$} & Generación y análisis de la información del sitio \\
\hline & & Identificación de conflictos \\
\hline & \multirow{3}{*}{ 4. Construcción Participativa } & Informativa \\
\hline & & Construcción \\
\hline & & Foros para el OEM \\
\hline & \multirow{2}{*}{ 5. Validación y Oficialización } & Marco normativo existente \\
\hline & & Evaluación ambiental estratégica \\
\hline & 6. Implementación & Estrategia de implementación \\
\hline & 7. Monitoreo & Evaluación de indicadores de línea base \\
\hline
\end{tabular}

8. Actualización / Ajuste

Figura 4. Etapas del proceso de ordenamiento espacial marino. Fuente: Marviva (2012).

Figure 4. Stages of the marine spatial planning process. Source: Marviva (2012).

marina y el impacto de los usos antrópicos, para generar los cimientos del OEM - El conocimiento y experiencia, de los usuarios de los ecosistemas marinos, sobre las consecuencias de la sobreexplotación, conflictos y/o potenciales conflictos, es de gran utilidad para el ordenamiento espacial marino. El uso de las herramientas tecnológicas disponibles nos puede ayudar en solventar falta de información de primera mano, por ejemplo, herramientas que fueron muy valiosas en este proceso fue el uso de sensores remotos y los registros de sistema de monitoreo de embarcaciones (VMS, Vessel monitoring system por sus siglas en inglés).

\section{Talleres de trabajo y entrevistas}

Se realizaron 2 talleres de trabajo, en octubre y noviembre del 2018, donde participaron los principales representantes de las autoridades nacionales en territorio (Capitanía de Puerto, Pesca y Ambiente), Gobiernos Locales, organizaciones de base locales, etc. (Vera, 2018).
Adicionalmente se entrevistó a actores claves representantes de gremios e intereses locales (pesca industrial, sector turístico y sector inmobiliario)

\section{Identificación y categorización de usos}

Se identificó las actividades humanas que se desarrollan en el área de análisis, y se determinaron los límites espaciales dentro de los que se realiza cada actividad. Existen actividades que se realizan en tierra, sin embargo, afectan directa y/o indirectamente a los ecosistemas o hábitats marinos (actividades terrestres con impacto marino); en estos casos, los espacios de mar bajo el efecto de estas actividades (por ejemplo, sedimentación, contaminación) deben ser identificados y delimitados, pues en cierta forma están siendo "usados" para verter aguas contaminadas.

Los usos identificados pueden ser muchos y para facilitar el análisis deberán ser organizados en categorías. 


\section{監 COSTAS}

\section{Análisis cartográfico de los usos}

Los usos identificados, con sus correspondientes valores fueron representados en un mapa de valoración de usos utilizando el Sistema de Información Geográfica (SIG). Los diversos usos valorados se organizaron por capas de información, de esta forma se logró visualizar de forma integral la valoración asignada a los diversos usos.

La información sobre la cobertura de usos y hábitats debidamente sistematizada y analizada fue generada en las fases previas y utilizada como insumo para identificar los traslapes entre hábitats y usos en el espacio marino costero sujeto al ordenamiento.

\section{Análisis de compatibilidad entre usos}

Se efectuó un análisis de la compatibilidad entre los diferentes usos y hábitats. Del mapa de usos, generado anteriormente, se pudo identificar aquellos sitios donde dos o más usos de interés convergen. Dos actividades presentes en un sitio pueden ser totalmente compatibles, compatibles bajo algunas regulaciones o totalmente incompatibles. El nivel de compatibilidad dependerá de las características de cada uso.

En el caso de relaciones de incompatibilidad fue relevante determinar la direccionalidad de esta incompatibilidad. Si la ocurrencia del uso A puede afectar al uso B, pero la ocurrencia del uso B no afecta al uso A, significa la existencia de incompatibilidad unidireccional. En aquellos casos donde la ocurrencia del uso A afecta al uso B, y la ocurrencia del uso B afecta al uso A, se está ante un caso de incompatibilidad bidireccional.

Una vez que se identificó y agrupó los usos que se podrían desarrollar en la zona a planificar, se procedió a realizar una compatibilización de estos.

La información sistematizada, sintetizada y traducida a un lenguaje sencillo, y mayoritariamente gráfico, aptos para los diferentes públicos meta, se socializó mediante conversatorios o talleres. Además de la divulgación de la información, el manejo de esta información por parte de los diversos sectores/actores es prerrequisito para continuar con el paso siguiente, o sea antes de iniciar el proceso de construcción participativa.

\section{Construcción participativa}

Para esta etapa del proceso, se trabajó bajo dos diferentes esquemas de intervención: entrevistas con líderes y talleres de trabajo. Por limitaciones de tiempo se realizaron 2 talleres en la zona, por lo que las entrevistas en el campo resultaron muy útiles para complementar la información del diagnóstico, también se toma en cuenta los lineamientos del POEMC (Plan de Ordenamiento Marino y Costero; Senplades, 2018) para el ordenamiento marino costero.

\section{Prefactibilidad}

Se define a la prefactibilidad como la etapa se precisa con mayor detalle la información y se incorporan datos adicionales que permitan descartar ciertas alternativas y perfeccionar las restantes en base a evaluaciones técnicas o económicas con la finalidad de definir cuál es la mejor alternativa (CEPAL, 2003).

Teniendo en cuenta que esta es una primera aproximación para intervenir en esta zona se desarrollaron los siguientes criterios para definir la factibilidad de implementar o no un proceso de ordenamiento espacial marino y costero, modificados en base a metodologías similares usadas para establecer la prefactibilidad de un sistema nacional de áreas marinas protegidas o evaluar la efectividad de manejo de un área protegida (Villegas et al., 2005; Cifuentes et al., 2000):

- Gobernabilidad. ¿Tienen las instituciones públicas la capacidad para cumplir y hacer cumplir las normas vigentes en el área de estudio?

- Sociales. ¿Tienen los habitantes del sector el interés de participar en un proceso de ordenamiento? 
- Capacidad técnica. ¿Existe la capacidad técnica en el país para implementar procesos de planificación y ordenamiento marino y costeros?

- Aspectos legales. ¿Existe el marco legal adecuado para implementar procesos de planificación y ordenamiento marino y costeros?

- Importancia económica. ¿La zona es de una importancia económica relevante a nivel local, regional, nacional e internacional)

- Importancia ambiental. ¿La zona es de una importancia ambiental destacada a nivel local, regional, nacional e internacional?

- Nivel de conflictividad. ¿El nivel de conflictividad en el área amerita la intervención del estado para implementar un proceso de ordenamiento? Aquí hay que tener en consideración que niveles muy extremos de conflictividad podrían reducir los impactos a corto y mediano plazo.

En base a estos criterios se estableció una categorización para cada uno de ellos mediante una escala descendente de 10 a $1(10-8-5-3$ - 1) dependiendo si la situación ameritaba o no iniciar un proceso de ordenamiento (tabla 2); sin embargo, para el criterio de nivel de conflictividad se usó una escala no lineal considerando que áreas como alta conflictividad o baja conflictividad podrían tener menor priorización en el momento actual porque es necesario fortalecer el marco legal para implementar planes de ordenamiento mandatorios o porque existen otras áreas prioritarias o no atendidas. La escala de evaluación tiene un rango de mínimo 7 a hasta un máximo de 70 puntos.

En base análisis realizado se califica cada uno de los criterios por un panel de expertos y aplicando la siguiente formula:

$$
\text { Prefactibilidad }=G o+S o+C t+I a+A l+I e+N c
$$

Se califica qué tan factible o no será realizar un proceso de ordenamiento marino costero local en un

Tabla 2. Criterios para definir la prefactibilidad de impulsar procesos de ordenamiento espacial marino y costero. Table 2. Criteria to define the pre-feasibility of promoting marine and coastal spatial planning processes.

\begin{tabular}{|l|c|l|l|}
\hline \multicolumn{2}{|c|}{ Gobernabilidad (Go) } & \multicolumn{1}{c|}{ Social (So) } \\
\hline $\begin{array}{l}\text { La coordinación de actividades entre instituciones para solucio- } \\
\text { nar problemas comunes se ejecuta eficientemente y se cumple y } \\
\text { se hace cumplir las normas vigentes. }\end{array}$ & 10 & $\begin{array}{l}\text { El apoyo de las comunidades hacia la iniciativa es } \\
\text { muy alto. }\end{array}$ & 10 \\
\hline $\begin{array}{l}\text { La coordinación de actividades entre instituciones para } \\
\text { solucionar problemas comunes es buena se cumple las normas } \\
\text { vigentes. }\end{array}$ & 8 & $\begin{array}{l}\text { El apoyo de las comunidades hacia la iniciativa es } \\
\text { alto. }\end{array}$ & 8 \\
\hline $\begin{array}{l}\text { La coordinación de actividades entre instituciones para solucio- } \\
\text { nar problemas comunes es buena, pero existe cierta demora en } \\
\text { la respuesta, se trata de cumplir las normas vigentes. }\end{array}$ & 5 & $\begin{array}{l}\text { El apoyo de las comunidades hacia la iniciativa es } \\
\text { mediano. }\end{array}$ & 5 \\
\hline $\begin{array}{l}\text { La coordinación de actividades entre instituciones para solucio- } \\
\text { nar problemas comunes es deficiente, los problemas tienden a } \\
\text { agravarse por falta de atención oportuna. }\end{array}$ & 3 & $\begin{array}{l}\text { El apoyo de las comunidades hacia la iniciativa es } \\
\text { bajo. }\end{array}$ & 3 \\
\hline $\begin{array}{l}\text { La coordinación de actividades entre instituciones para solucio- } \\
\text { nar problemas comunes es deficiente, los usuarios no confían } \\
\text { en las autoridades locales. }\end{array}$ & 1 & $\begin{array}{l}\text { El apoyo de la comunidad hacia la iniciativa es muy } \\
\text { bajo o no existe. }\end{array}$ & 1 \\
\hline Elaboración propia, 2018. & \\
\hline
\end{tabular}


Tabla 2. Criterios para definir la prefactibilidad de impulsar procesos de ordenamiento espacial marino y costero.

Table 2. Criteria to define the pre-feasibility of promoting marine and coastal spatial planning processes.

\begin{tabular}{|c|c|c|c|}
\hline Capacidad Técnica $(\mathrm{Ct})$ & & \multicolumn{2}{|l|}{ Importancia Ambiental (Ia) } \\
\hline $\begin{array}{l}\text { Existe actualmente en el país una alta capacidad técnica para } \\
\text { realizar procesos de ordenamiento marino costeros. }\end{array}$ & 10 & $\begin{array}{l}\text { La zona cuenta con una importancia ambiental, } \\
\text { ecológica a nivel internacional. }\end{array}$ & 10 \\
\hline $\begin{array}{l}\text { Existe actualmente en el país una buena capacidad técnica para } \\
\text { realizar procesos de ordenamiento marino costeros. }\end{array}$ & 8 & $\begin{array}{l}\text { La zona cuenta con una importancia ambiental, } \\
\text { ecológica a nivel nacional. }\end{array}$ & 8 \\
\hline $\begin{array}{l}\text { Existe actualmente en el país una capacidad técnica mediana } \\
\text { para realizar procesos de ordenamiento marino costeros. }\end{array}$ & 5 & $\begin{array}{l}\text { La zona cuenta con una importancia ambiental, } \\
\text { ecológica a nivel regional. }\end{array}$ & 5 \\
\hline $\begin{array}{l}\text { Existe actualmente en el país una capacidad técnica baja para } \\
\text { realizar procesos de ordenamiento marino costeros. }\end{array}$ & 3 & $\begin{array}{l}\text { La zona cuenta con una importancia ambiental, } \\
\text { ecológica a nivel local. }\end{array}$ & 3 \\
\hline $\begin{array}{l}\text { Existe actualmente en el país una capacidad técnica muy baja } \\
\text { o no existe para realizar procesos de ordenamiento marino } \\
\text { costeros. }\end{array}$ & 1 & $\begin{array}{l}\text { La zona cuenta con una escasa importancia ambien- } \\
\text { tal o ecológica. }\end{array}$ & 1 \\
\hline Aspectos Legales (Al) & & \multicolumn{2}{|l|}{ Importancia económica (Ie) } \\
\hline $\begin{array}{l}\text { El complejo de leyes y normas existentes es muy claro y abarca } \\
\text { todos los niveles de la jurisprudencia del estado sobre el orde- } \\
\text { namiento espacial marino y costero, garantizando el buen uso y } \\
\text { aprovechamiento de los recursos marinos y costeros. }\end{array}$ & 10 & $\begin{array}{l}\text { Hay un elevado aporte de beneficios directos hacia } \\
\text { la comunidad e incluso a nivel nacional. }\end{array}$ & 10 \\
\hline $\begin{array}{l}\text { Existe el complejo legal citado arriba, no hay superposición, } \\
\text { pero existen lagunas específicas que no llegan a afectar el orde- } \\
\text { namiento espacial marino y costero }\end{array}$ & 8 & $\begin{array}{l}\text { Hay un mediano a alto aporte de beneficios hacia la } \\
\text { comunidad. Importancia a nivel provincial. }\end{array}$ & 8 \\
\hline $\begin{array}{l}\text { Existe un complejo de leyes y normas sobre el ordenamiento } \\
\text { espacial marino y costero, con algunas lagunas específicas y } \\
\text { ligeras superposiciones entre leyes. }\end{array}$ & 5 & $\begin{array}{l}\text { el aporte de beneficios hacia la comunidad es medi- } \\
\text { ano. Importancia a nivel regional. }\end{array}$ & 5 \\
\hline $\begin{array}{l}\text { Existen algunas leyes y normas que propician la sobre el } \\
\text { ordenamiento espacial marino y costero, pero con marcados } \\
\text { conflictos entre las mismas y muchos vacíos. }\end{array}$ & 3 & $\begin{array}{l}\text { los beneficios perceptibles hacia la comunidad son } \\
\text { bajos. Importancia a nivel local. }\end{array}$ & 3 \\
\hline $\begin{array}{l}\text { No se cuenta con leyes y normas generales que normen el } \\
\text { ordenamiento espacial marino y costero. }\end{array}$ & 1 & $\begin{array}{l}\text { los beneficios perceptibles hacia la comunidad son } \\
\text { bajos o locales. }\end{array}$ & 1 \\
\hline \multicolumn{4}{|l|}{ Nivel de conflictividad (Nc) } \\
\hline $\begin{array}{l}\text { Hay un nivel de conflictividad muy alto, con muchos actores y } \\
\text { se llega frecuentemente a la violencia. }\end{array}$ & 5 & & \\
\hline $\begin{array}{l}\text { Hay un nivel de conflictividad alto, con muchos actores, pero } \\
\text { es posible resolverlos a largo plazo través del diálogo. }\end{array}$ & 10 & & \\
\hline $\begin{array}{l}\text { Hay un nivel de conflictividad mediano, con muchos actores, } \\
\text { pero es posible resolverlos a través del diálogo. }\end{array}$ & 8 & & \\
\hline $\begin{array}{l}\text { Hay un nivel de conflictividad bajo, con pocos actores, pero es } \\
\text { posible resolverlos a través del diálogo. }\end{array}$ & 3 & & \\
\hline $\begin{array}{l}\text { Hay un nivel de conflictividad muy bajo, con pocos actores, } \\
\text { pero es posible resolverlos a través del diálogo. }\end{array}$ & 1 & & \\
\hline Elaboración propia, 2018. & & & \\
\hline
\end{tabular}


área determinada, especialmente para realizar y priorizar intervenciones piloto en momentos en que los recursos (económicos, técnicos, etc.) son escasos en base a una escala definida si es viable o no implementar un proceso de ordenamiento en este momento (tabla 3).

$\mathrm{Y}$ aunque, siempre es y será recomendable iniciar un proceso de ordenamiento marino y costero, también es importante identificar regiones con mayores posibilidades de éxito o que se logre resultados de impacto, para poder después replicar en las demás zonas, y es en ese sentido que se evalúa esta prefactibilidad.

\section{Resultados}

\section{Mapa de actores}

La mayoría de los actores en donde destacan las comunidades locales, los gobiernos autónomos descentralizados, así como las organizaciones de usuarios (i.e. pescadores, servidores turísticos) tienen un gran interés en participar y están de acuerdo en iniciar un proceso de participación (figura 5). Sin embargo, un actor principal no local y perteneciente a otras comunidades son los pescadores industriales, quienes inclusive provienen de otras provincias (los principales puertos pesqueros se encuentran en Manta, Manabí; Santa Rosa, Santa Elena; Posorja, Guayas) por lo que hay que tomar esto en cuenta en futuros procesos.

\section{Descripción de las principales actividades marinas y costeras}

Para la definición del territorio y sus usos se identificó las actividades económicas predominantes en la zona que incluyen la pesca, la acuicultura, y en menor grado el turismo costero. A pesar de ser considerado como un solo territorio, en la parte terrestre está dividido en varias jurisdicciones políticas (tres cantones) y varías instituciones nacionales con competencias
Tabla 3. Ponderación de prefactibilidad de iniciar procesos de ordenamiento.

Table 3. Weighting of the pre-feasibility of starting ordering processes.

\begin{tabular}{|c|c|}
\hline Suma de los criterios & Prefactibilidad \\
\hline $57-70$ & Muy alta \\
\hline $43-56$ & Alta \\
\hline $29-42$ & Media \\
\hline $15-28$ & Baja \\
\hline $7-14$ & Muy baja \\
\hline
\end{tabular}

sectoriales donde predomina la falta de una visión integral y trabajo coordinado (Iturralde, 2018).

\section{Productividad}

En el área de estudio se reportan valores de productividad primaria normales de la región, pero incluso valores altos, por encima de $0.5 \mathrm{mg} \cdot \mathrm{m}^{3}$ clorofila, en base a sensores remotos MODIS-aqua, especialmente en la época lluviosa donde las descargas de nutrientes provenientes de los ríos activan núcleos de productividad especialmente en la zona sur (figura 6).

\section{Pesquerías artesanales}

La pesca ha sido desde tiempos precolombinos de gran importancia para este sector (la cultura Jama-Coaque durante el periodo de tiempo $500 \mathrm{aC}$ Hasta $1531 \mathrm{dC}$ fue ejemplo de uso de recursos marinos que se representan en su iconografía; Quelal, 2013). En relación con las pesquerías artesanales, el Instituto Nacional de Pesca (INP, 2013) identificó en el área de estudio 25 caletas pesqueras artesanales que se dedican principalmente al uso del trasmallo de fondo, enmalle de fondo, enmalle de superficie, ata- 


\section{Fin \\ COSTAS}

Revista Costas, Vol. Esp. 2, 2021

\begin{tabular}{|l|l|l|}
\hline $1-$ Publico & $3-$ Comunidades & $5-$ Academia \\
\hline $2-$ Privado & $\begin{array}{l}4-\text { Organizaciones no } \\
\text { gubernamentales } / \\
\text { Cooperación }\end{array}$ & $\begin{array}{l}6-\text { Medios de } \\
\text { comunicación }\end{array}$ \\
\hline
\end{tabular}

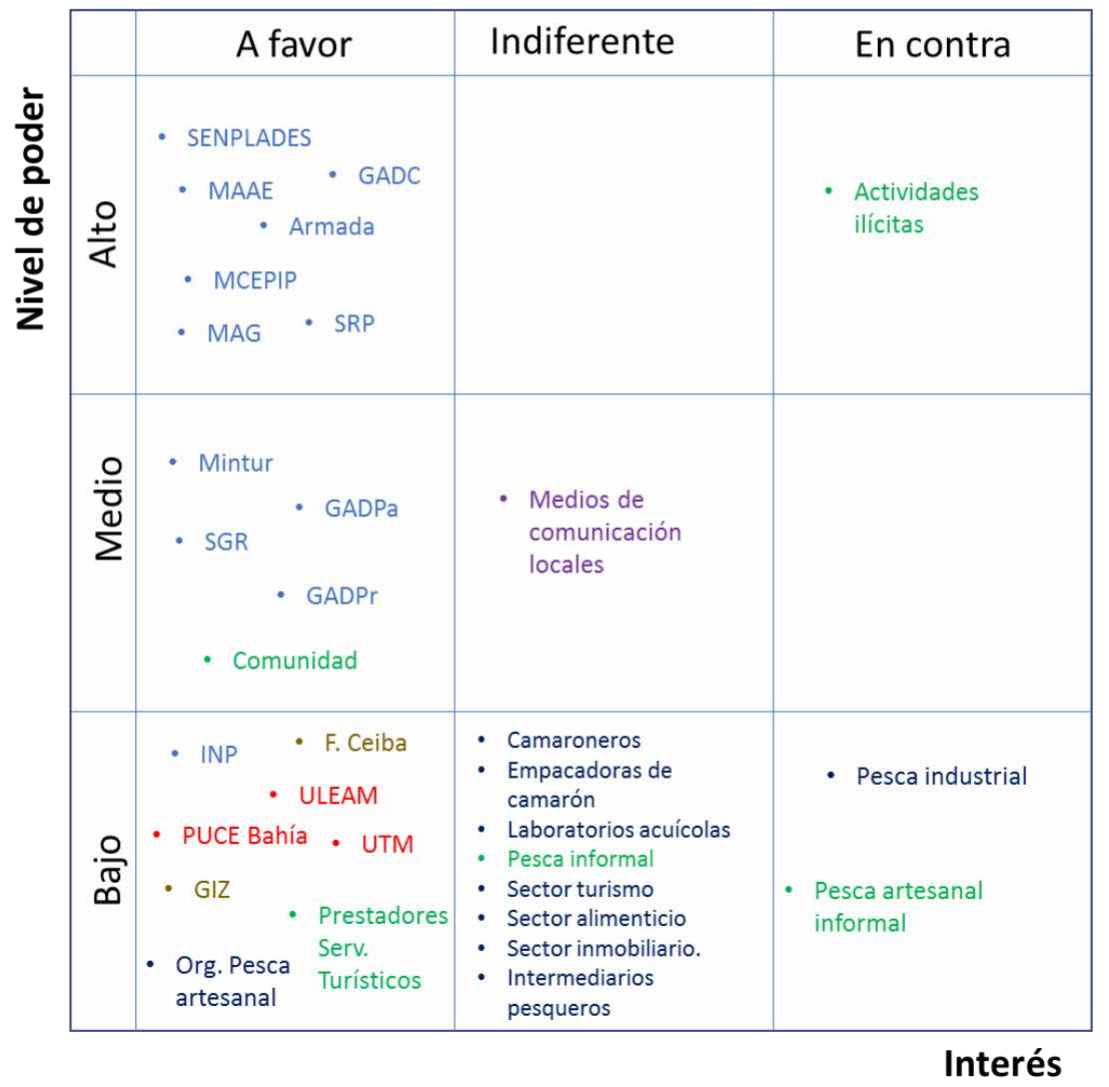

Figura 5. Mapa de actores relacionados con el OEMC en la zona de Manabí Norte. Fuente: Vera (2018).

Figure 5. Map of actors related to the OEMC in the Manabí Norte area. Source: Vera (2018).

rraya, espinel de fondo, línea troleo a la rastra, línea de mano de fondo, artes orientadas a la captura de peces demersales, langosta, camarón marino y pelágicos grandes (Figura 7).

En el área se encuentran 2 de los 9 principales puertos artesanales monitoreados permanentemente por el Instituto Público de Investigación de Acuicultura y Pesca (IPIAP) en el sector de Pedernales y Bahía de Caráquez; ambos puertos representan el $0.71 \%$ del total nacional de los desembarques de las pesquerías artesanales alcanzando un valor máximo al año de 429 t al 2013 (figura 8). Mientras este volumen de desembarque pesquero puede representar una pequeña cantidad a nivel nacional, es de una gran importancia para la economía local (figura 9). Las descargas anuales en promedio son 190 t por año 

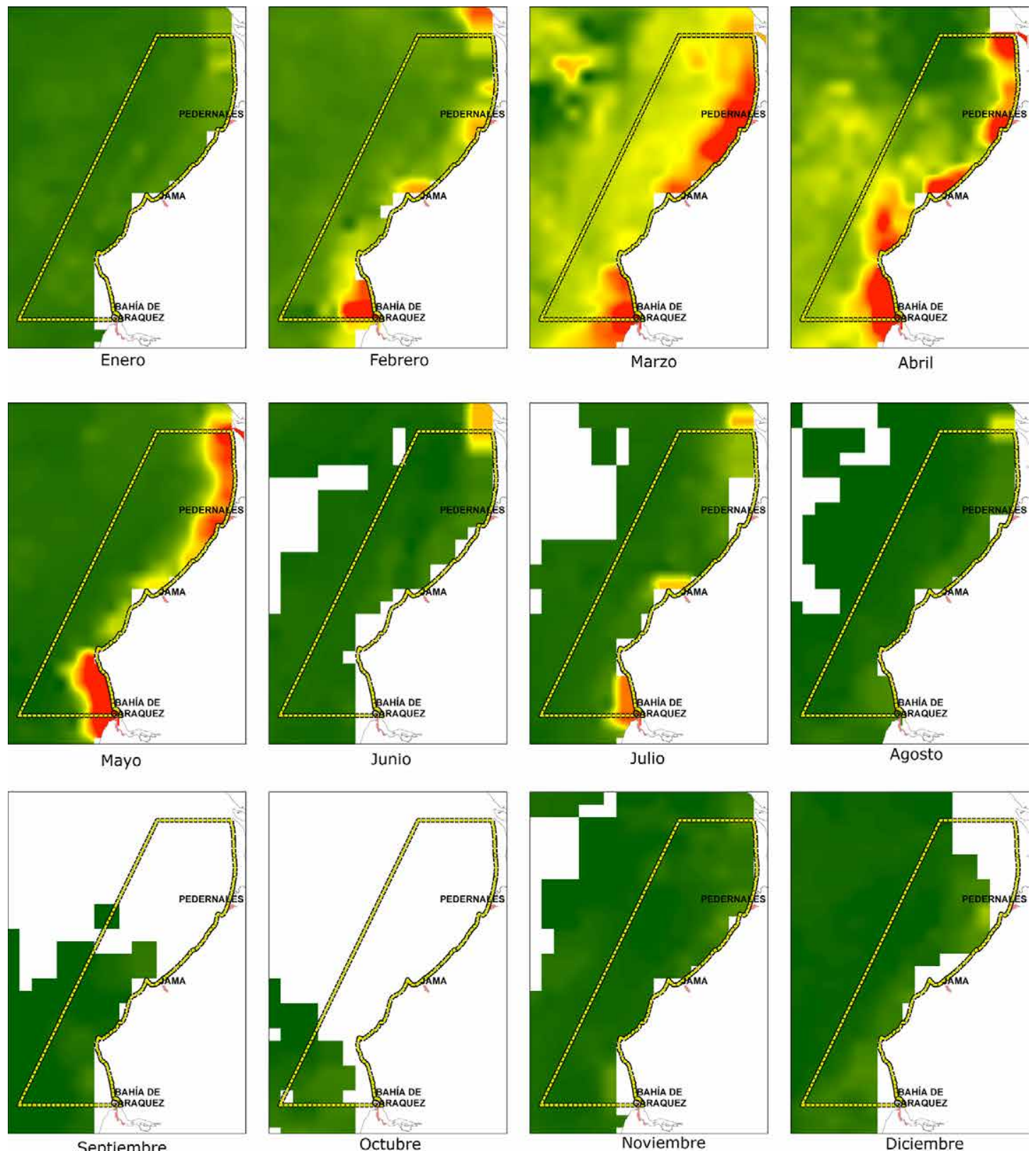

Área de estudio
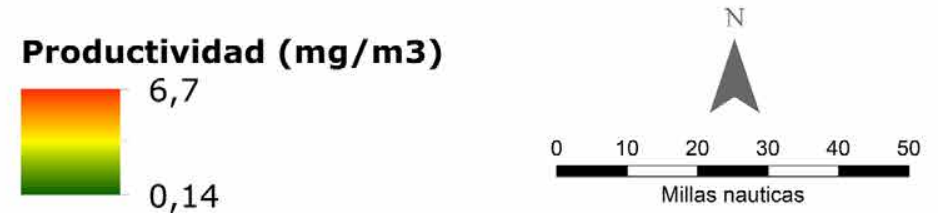

Figura 6. Productividad primaria mensual $\left(\mathrm{mg} . \mathrm{m}^{3} \mathrm{Cla}\right)$ durante el 2017 en la zona de estudio.

Figure 6. Monthly primary productivity $\left(\mathrm{mg} . \mathrm{m}^{3} \mathrm{Cla}\right)$ during 2017 in the study area. 


\section{照 \\ COSTAS}

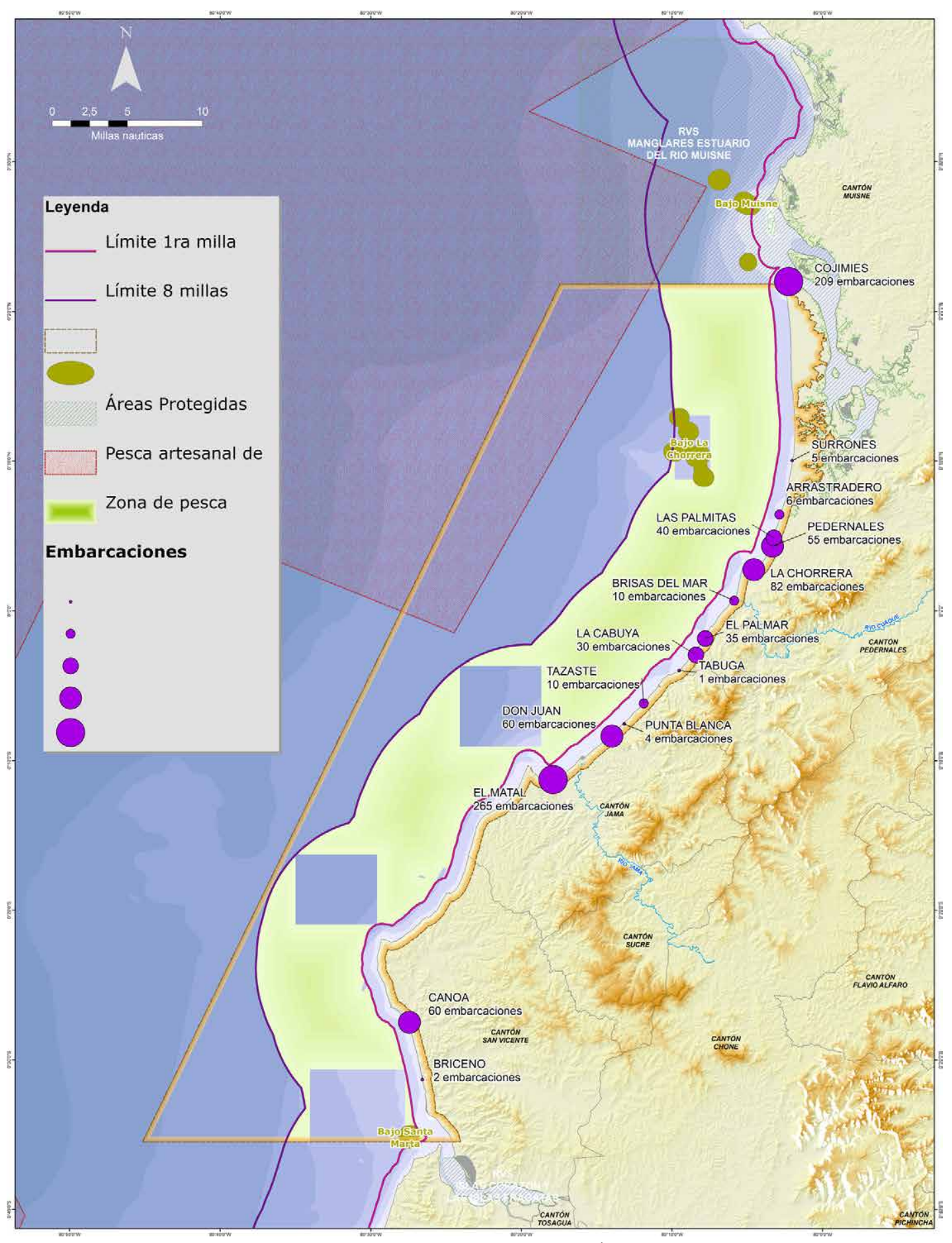

Figura 7. Uso: Pesca artesanal.

Figure 7. Use: Small scale fishing. 
Iturralde, Vera \& Coronel
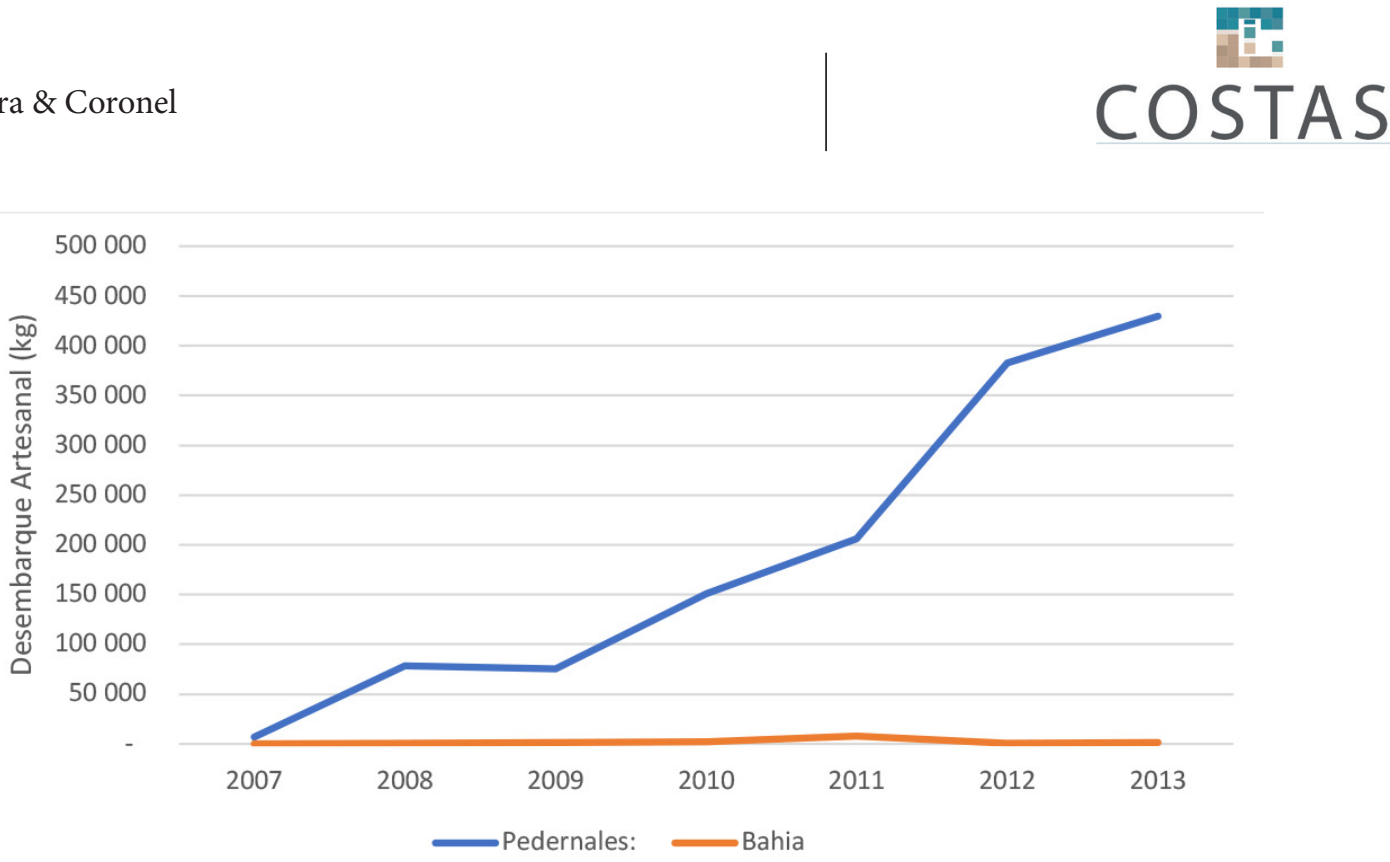

Figura 8. Desembarques de pesca artesanal en el área de estudio. Fuente: VMAP (2014).

Figure 8. Artisanal fishing landings in the study area. Source: VMAP (2014).

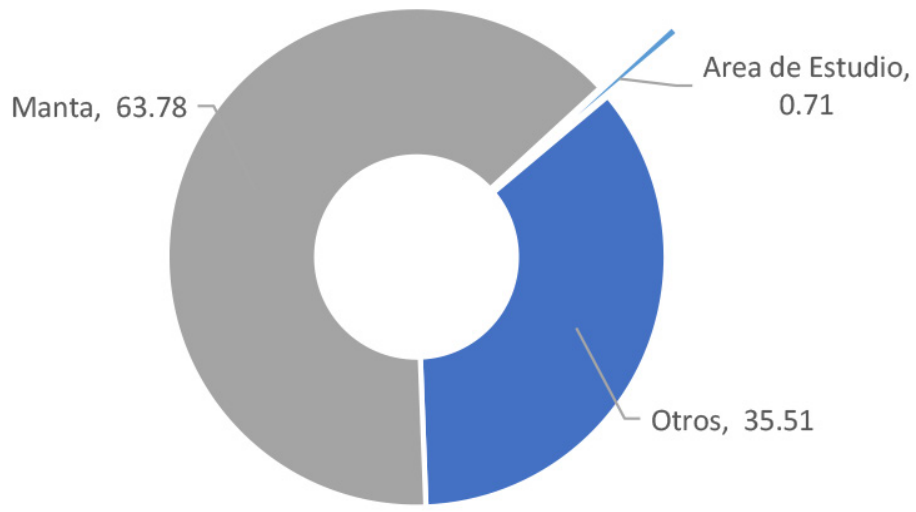

Figura 9. Proporción de desembarques en 9 puertos artesanales del Ecuador (2007-2013). Fuente: VMAP (2014).

Figure 9. Proportion of landings in 9 artisanal ports of Ecuador (2007-2013). Source: VMAP (2014).

en Pedernales, mientras que en Bahía de Caráquez se descargaron hasta $2 \mathrm{t}$ al año. El principal destino de la pesca obtenida en el área es principalmente para uso local y las ciudades de Pedernales, Santo Domingo, Guayaquil, Quito y Manta (INP, 2013).

Para estimar el esfuerzo pesquero se utilizó el número de embarcaciones. El estudio antes menciona- do del IPIAP reporta un total de 1118 embarcaciones artesanales de diferentes tipos. La que predomina es la "fibra", embarcación hecha con fibra de vidrio de un poco más de $7 \mathrm{~m}$ de eslora (largo), con motor fuera de borda de mediana potencia (entre 40 a 75 caballos de fuerza, HP) (INP, 2013). 


\section{監 \\ COSTAS}

Las caletas pesqueras con mayor número de embarcaciones son El Matal (265), Cojimíes (209) y Los Perales con 111 embarcaciones (figura 10). Sin embargo, hay que mencionar que existe un flujo no cuantificado de pescadores artesanales de otras jurisdicciones cercanas que pueden pescar dentro de la zona y desembarcan en caletas pesqueras cercanas, como por ejemplo Bahía de Caráquez y adyacentes. En el área se reconocen dos tipos principales de pesca artesanal (Mamani, 2013): costera y de altura (tabla 4), la pesca de altura puede llegar hasta al oeste de las Islas Galápagos y se enfoca principalmente a la pesca de pelágicos grandes (Martínez-Ortíz et al., 2015).
Durante las entrevistas, así como en los registros analizados, las especies que predominan en el área de estudio son: cabezudo (Caulolatilus affinis), el camotillo (Diplectrum spp), el camarón langostino (Litopenaeus spp) y la langosta (Panulirus spp). En los talleres de trabajo fue recurrente el comentario "por culpa de la pesca industrial (polivalente y chinchorrera) ya no pescan en el área costera y tienen que ir a pescar mar afuera, pesca de altura, grandes pelágicos, como el dorado, wahoo, atún entre otros" -Alberto Vélez, presidente de la Aso. Pescadores de San Vicente.

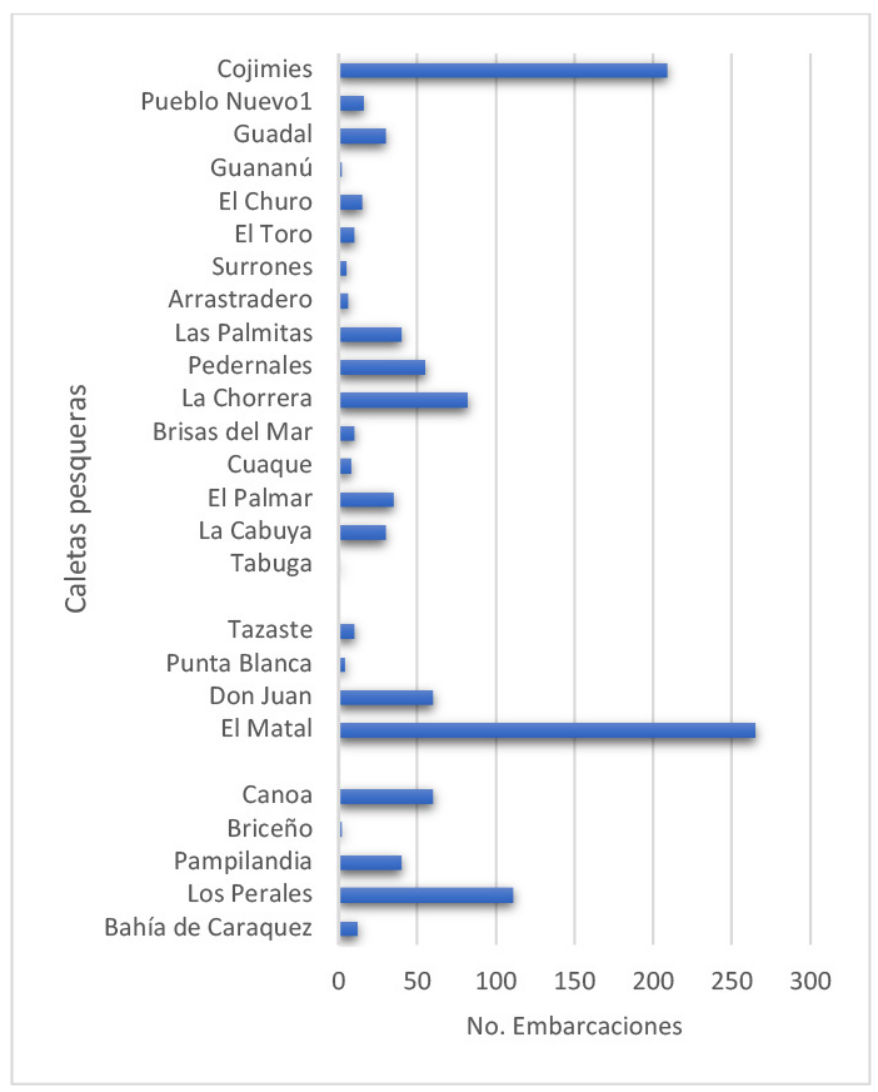

Figura 10. Caletas pesqueras en el área de estudio( número de embarcaciones). Fuente: INP (2013).

Figure 10. Fishing coves in the study area (number of vessels). Source: INP (2013). 
Tabla 4. Características de los tipos de pesquerías artesanales en El Matal, Jama. Fuente: Mamani (2013).

Table 4. Characteristics of the types of artisanal fisheries in El Matal, Jama. Source: Mamani (2013).

\begin{tabular}{|l|l|l|}
\hline & \multicolumn{1}{|c|}{ Costera } & \multicolumn{1}{|c|}{ de Altura } \\
\hline Distancia $(\mathrm{mn})$ & $5-15$ & $\begin{array}{l}\text { Desde los 25 hasta las 90 millas aprox- } \\
\text { imadamente }\end{array}$ \\
\hline Eslora $(\mathrm{m})$ & $5 \mathrm{a} 7$ & $7-12$ \\
\hline Motor fuera de borda (hp) & $35-45$ & $75-85$ \\
\hline Especies objetivo & $\begin{array}{l}\text { La albacora, el bonito, el cabezudo, el camotillo, el } \\
\text { chorrillo, el pámpano, el róbalo, el wahoo, entre otros; } \\
\text { y especies de crustáceos, camarones, langostinos, entre } \\
\text { otro }\end{array}$ & $\begin{array}{l}\text { Peces grandes como el bonito, el do- } \\
\text { rado, el picudo, el rabón, la albacora, } \\
\text { entre otros. }\end{array}$ \\
\hline Duración de la faena de pesca & 1 día & De dos a tres días \\
\hline
\end{tabular}

Se identificó un gran vacío de conocimiento como es la falta de información sobre el estado de las poblaciones de peces de los que dependen estas comunidades costeras, por lo que, si bien se conoce que están aumentando sus desembarques en volúmenes no se puede conocer si esta actividad es sustentable actualmente.

\section{Pesca industrial}

En él área se ha reportado tanto la pesca industrial (chinchorrera, pesca a mediana escala de pelágicos pequeños, y polivalente, pesca de arrastre industrial de merluza y camarón), tanto fuera como dentro de la zona de reserva de las 8 millas náuticas e incluso dentro de la misma milla (comentarios de dirigentes pesqueros taller Jama, figura 11).

\section{Pesca polivalente}

En el 2012 se prohibió la pesca de arrastre de camarón langostino en todo el territorio nacional, por lo que se procedió a dar de baja a ciertas embarcaciones de las 105 que funcionaban en ese momento $\mathrm{y}$ algunas de ellas fueron reconvertidas para aprovechar otros recursos. Por ejemplo, desde el 2012 se autorizó la pesca demersal de merluza para 30 embarcaciones, estas embarcaciones en el 2015 fueron, de forma experimental, autorizadas adicionalmente a pescar camarón blanco y café, bajo el siguiente criterio emitido por la autoridad pesquera: "con la finalidad de minimizar el impacto socio económico resultante de la profundización, debido al evento El Niño 2015 y 2016, categorizado como fuerte, de la Merluza (Merluccius gayi), y a efecto de desarrollar la alternabilidad del esfuerzo pesquero y una posible forma de conservación y manejo sustentablemente de distintos recursos objetivos, efectuó la 'Pesca Piloto de investigación del Camarón rojo (Farfantepenaeus brevirostris) y el Camarón café ( $F$ californiensis) fuera de las ocho millas náuticas' como actividad complementaria a la pesca industrial de merluza en la costa ecuatoriana”. Sin embargo, este permiso se ha venido renovando desde 2017 hasta la actualidad.

En el área de estudio están autorizadas las actividades de 5 embarcaciones, 3 de Guayaquil y 2 de Esmeraldas, y solo se les permite desembarcar su pesca en los puertos de Esmeraldas (Esmeraldas), Puerto López, Jaramijó y Manta (Manabí), Anconcito (Santa Elena), Posorja (Guayas) y Puerto Bolívar (El Oro) (INP, 2016).

Estas embarcaciones durante el periodo 20152016 tuvieron actividad frente a El Matal y frente a Pedernales, lo cual fue corroborado por los pescadores artesanales, tanto en el taller de octubre como en el de noviembre de 2018. 


\section{ren \\ COSTAS}

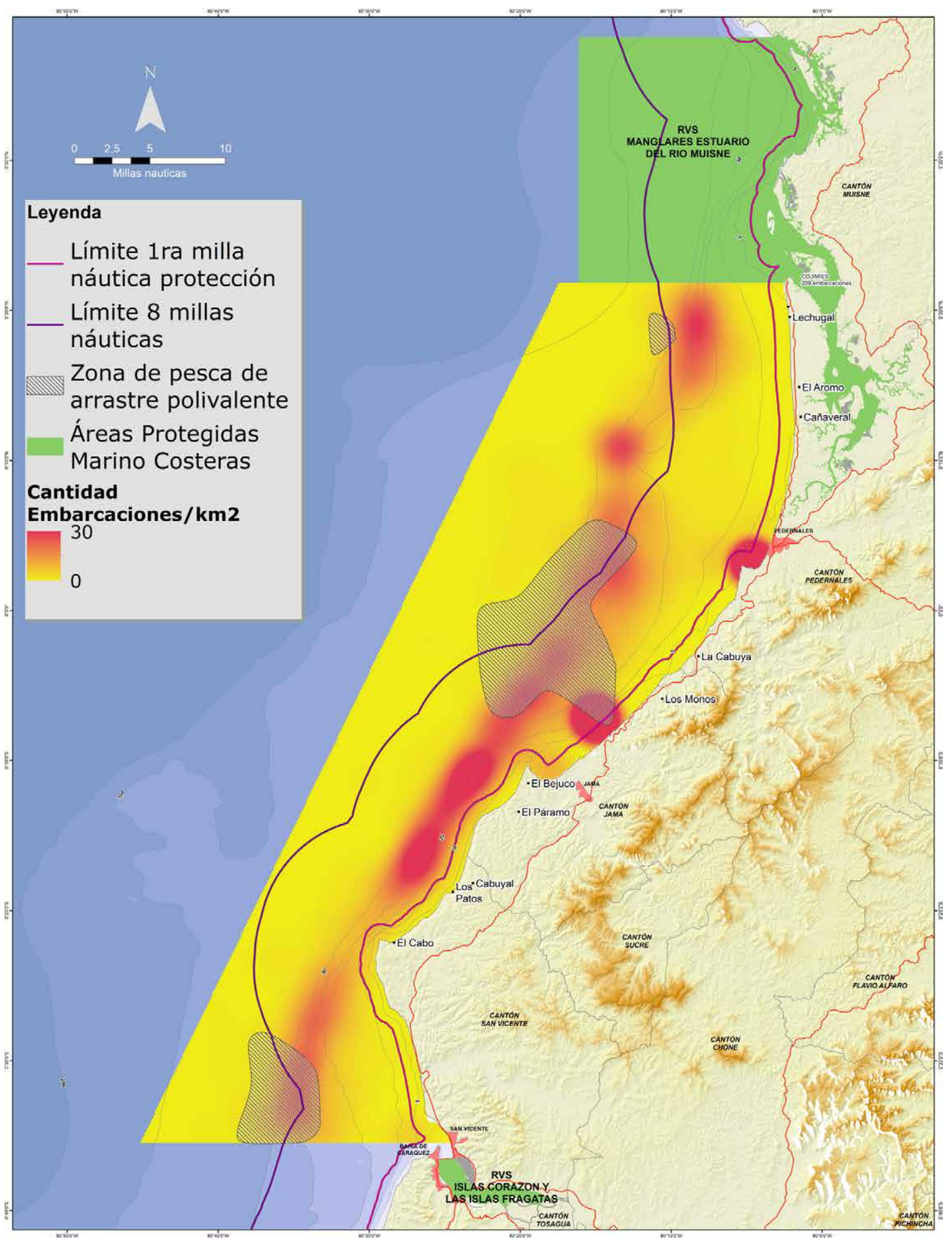

Figura 11. Uso: Pesca industrial.

Figure 11. Use: Industrial fishing. 


\section{re \\ COSTAS}

\section{Pesca de Pelágicos Pequeños}

La pesca comercial de peces pelágicos pequeños se inició en la década del sesenta para capturar pinchagua y chuhueco en áreas cercanas a la línea de costa dentro de las 10 millas náuticas. Esta flota opera todo el año durante la fase de luna nueva (oscura), sus salidas son diarias y se realizan en la noche.

Tradicionalmente, sus áreas de pesca son a lo largo de toda la costa ecuatoriana, especialmente entre el Golfo de Guayaquil y frente a la provincia de Manabí. Las embarcaciones de menor autonomía pescan hasta la milla náutica 30 y las de mayor autonomía hasta más allá de las $100 \mathrm{mn}$.

En el 2018 se reportan de 267 embarcaciones para la captura de pelágicos pequeños principalmente en los puertos de Jaramijó, Machalilla, Manta, Salango, Los Arenales de Crucita, Anconcito, Monteverde, Chanduy y Posorja (Ormaza et al., 2018). Esta pesquería se redujo drásticamente desde mediados de la década de los ochenta, a partir del 2005 esta tendencia se estabilizó, mostrando un nuevo declive en el 2010 (Alava et al., 2015).

Igualmente, en las localidades de Jaramijó, Bahía de Caráquez, Crucita (Prov. de Manabí) y Palmar (Prov. de Santa Elena), se realizan desembarques de peces pelágicos pequeños (como son por ejemplo la pinchagua, Etrumeus teres; sardina, Sardinops sp.) por parte de la flota cerquera sardinera, con una capacidad menor a 35 Toneladas de Registro Neto. También la disminución en las tasas de captura de estas especies, en estas áreas, ha sido asociada al uso de "pantallas" por parte de los barcos sardineros que operan en la zona, lo que ha originado una serie de conflictos entre los pescadores artesanales e industriales por la captura de individuos con longitudes pequeñas (inferiores a la talla media de madurez sexual), así como también de otras especies consideradas como pesca blanca (anchoa, chazo, hojita, mojarra, lenguado, etc.) (González et al., 2008).
A lo largo de su historia, ha habido un conflicto permanente de este sector con la pesca artesanal, ellos aducen que su pesquería también es artesanal o semiindustrial (Gobierno Autónomo Descentralizado Parroquial [GADP] Cojimíes, 2015), a pesar de ser catalogada como industrial por la de entonces vigente Ley de Pesca y Desarrollo Pesquero. En el 2008 estas pesquerías fueron recategorizados como Industriales y como tal su ámbito de acción se estableció a más allá de las 8 millas náuticas desde la costa, antes eran considerados como semiindustriales (una categoría que no existía en la Ley de Pesca vigente en ese momento). Sin embargo, en el 2010 les fue otorgado una medida cautelar constitucional que les permitía pescar dentro de la zona de reserva de la pesca artesanal (La Hora 2010, El Diario 2011. El Telégrafo 2014, El Productor 2020). La misma que fue finalmente resuelta por la Corte Constitucional mediante sentencia 0084-10-JC en la cual se confirma la revocatoria de la medida cautelar.

En el área de estudio, la pesquería de pelágicos pequeños se desarrolla frente la parte norte de Manabí y representa mucho menor volumen que en relación con el Golfo de Guayaquil, la zona de pesca tradicional de este recurso; durante el periodo 1998 al 2007 se reportan valores anuales entre 100 a 300 toneladas al año al norte de Bahía de Caráquez del recurso pinchagua, no se reportan otras especies (González et al., 2008).

\section{Maricultura}

\section{Cultivo de camarones}

En los alrededores del área de estudio la presencia de granjas camaroneras es evidente, principalmente en los estuarios de Chone y Muisne, las cuales están asociadas a la degradación de la calidad ambiental de estos (deforestación y pérdida de manglares), especialmente del estuario del Rio Chone. No obstante, la distribución de camaroneras no se limita a los es- 


\section{rin \\ COSTAS}

Revista Costas, Vol. Esp. 2, 2021

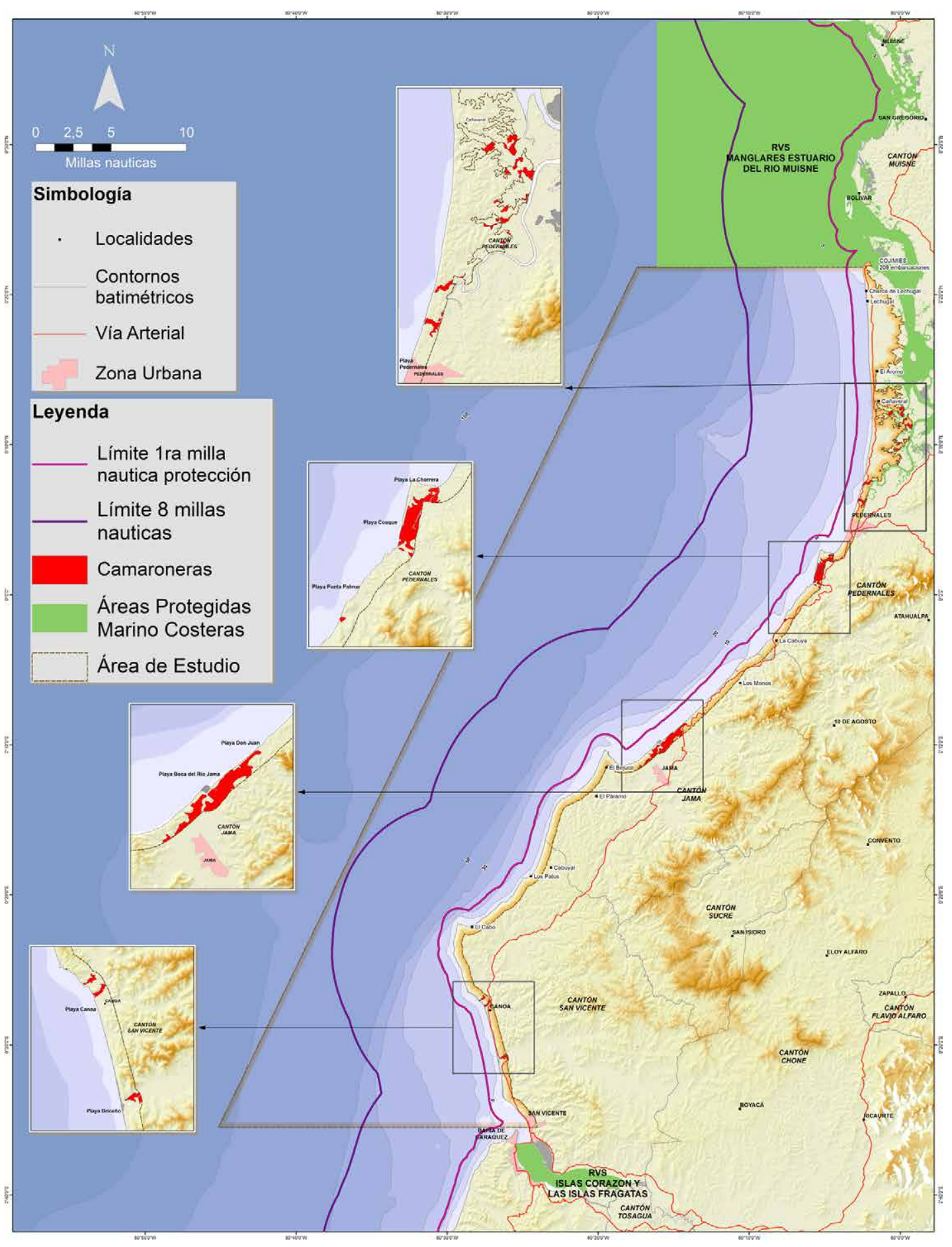

Figura 12. Uso: Granjas camaroneras.

Figure 12. Use: Shrimp farms. 


\section{re \\ COSTAS}

tuarios antes mencionados, presentándose también alrededor de Jama y Cojimíes (figura 12).

Tanto en los cantones de Jama y Cojimíes, antes de la aparición del sindrome de la mancha blanca (1999) había producciones regulares y aceptables, pero después las producciones cayeron significativamente y la mayoría de las instalaciones fueron cerradas. Pero en años recientes se ha visto una pequeña recuperación respecto a sus volúmenes de producción, pero no han alcanzado los niveles previos a la mancha blanca (Alcívar et al., 2011 Santos et al., 2011).

En el área de estudio se encuentran 1227 ha de granjas camaroneras (Coronel, 2018) y se reconoce que son un importante dinamizador de la economía en el sector. Por ejemplo, solo al observar la diversidad de distribuidores de productos acuícolas y demás temas asociados (bombas de agua, etc.) localizados en ambos cantones.

Respecto a las piscinas de acuicultura se mencionaron los siguientes asuntos de manejo en los talleres:

- Contaminación de agua y mortalidad de especies bioacuáticas por los químicos que utilizan

- Proliferación de granjas acuícolas de agua continental en los ríos de la zona especialmente en la parte alta del río Jama, las mismas que afectan directamente los cursos de agua de los cuales dependen estas poblaciones.

\section{Cultivo en mar abierto (peces, moluscos y algas)}

Una actividad a la que se ha dado mucho interés en los últimos años es el cultivo de peces en jaulas en mar abierto (i.e., maricultura); según Chavarría (2015) los mejores sitios para desarrollar la maricultura de peces en jaula del país se localizan en el área de estudio, debido a sus condiciones oceanográficas y ambientales, no obstante, la falta de acceso a vías e infraestructura es un limitante para esta actividad.

Stratega (2010) identificó a Jama como una de las que mayores posibilidades de establecer un proyecto piloto de acuicultura marina, esto dentro de las 10 caletas pesqueras analizadas (Tonchigüe, Mompiche, Jama, Jaramijó, San Mateo, Ayangue, Santa Rosa, Anconcito, Playas-Engabao, Puerto Bolívar); sin embargo, esto no descarta que en otras caletas pesqueras podrían ser aprovechadas para el desarrollo de granjas familiares de cultivos de macroalgas o de moluscos (ostras) (Stratega, 2010).

En el área de estudio existe un cultivo experimental de ostras en la desembocadura del río Chone, administrado por la Universidad Técnica de Manabí, se ha entregado una concesión de una hectárea a una organización de pescadores para el cultivo de camarón en jaula, -cuyo estado operativo al momento se desconoce-, y otra concesión de similares características está en proceso de adjudicación (Subacua, 2018).

Respecto a la maricultura se mencionaron los siguientes asuntos de manejo en los talleres:

- Hay la expectativa de implementar acciones de maricultura en la zona, especialmente en las bahías de Pedernales y Jama, pero su viabilidad ambiental, social y económica debe de ser evaluada previamente.

\section{Laboratorios de larvas}

En todo el sector se encuentra la presencia de laboratorios de producción de larvas; al respecto, las fuentes consultadas indican que éstos totalizan aproximadamente 20 laboratorios en Pedernales y 9 en Jama. En el 2018 hubo mucho interés en producir larva de camarón por una reducción a la producción de Santa Elena y El Oro asociada a un exceso de algas, lo que dirigió los esfuerzos de producción de larvas a la zona norte de Manabí. Una vez resuelta la situación en las otras provincias, la mayoría de los laboratorios de la zona no estuvieron en producción (octubre 2018).

Respecto a los laboratorios de larvas se mencionaron los siguientes impactos y asuntos de manejo en los talleres: 


\section{照 \\ COSTAS}

- Interacción con turistas, las tuberías de captación de agua pueden lastimar a los turistas al caminar por las playas.

- Afectación a la calidad de agua por las descargas.

- Solicitan se revise la normativa para poder vender las "camaronas (hembras grávidas)" que era un importante recurso económico y ahora se vende como camarón normal.

- Permisos ambientales se otorgan sin verificar si la actividad es compatible con el uso de suelo.

\section{Procesadoras de productos acuícolas}

Existe en la zona 3 empacadoras de camarón (INP, 2018), sin embargo, no se mencionó ningún impacto generado por estas durante los talleres, pero es necesario verificar el fiel cumplimiento de la normativa ambiental, debido a que este tipo de actividad puede causar grandes impactos por su afectación a la calidad de agua.

\section{Turismo}

El desarrollo de la actividad turística en la zona en muy importante existe una planta hotelera de 59 establecimientos y 3044 camas. La hotelería local está muy relacionada con el turismo interno especialmente proveniente de Quito.

Este sector fue fuertemente afectado por el terremoto del 2016 durante el cual el 70\% de la planta hotelera del sector de Pedernales fue afectado, no así el de Cojimíes. En el sector de Pedernales se pueden llegar a receptar hasta 60 mil turistas en los feriados nacionales, mientras que en San Vicente llegan a recibir hasta 20 mil turistas.

El sector turístico es una importante fuente de empleo local. En el cantón Jama se emplean 50 personas, en Pedernales 599 y en San Vicente 379 (Paguay, 2016).

\section{Atractivos turísticos}

En los 3 cantones se registraron 91 atractivos turísticos de los cuales el $50.6 \%$ son atractivos naturales y el $49.6 \%$ son manifestaciones culturales (Mintur, 2004).

En cuanto a los atractivos naturales, predominan las playas (24 atractivos, $52.2 \%$ ) siendo la Playa de Canoa considerada como de categoría mundial, 12 como atractivos locales y 13 como atractivos nacionales (Mintur, 2004; tabla 5).

Otros atractivos naturales son: bosques (10 atractivos, $21.7 \%$ ), ríos 7 atractivos (15.2\%), el resto de los atractivos son rasgos geológicos, estuarios y áreas protegidas (figura 13).

A pesar de los atractivos mencionados, estos cantones no se encuentran entre los 18 principales destinos turísticos del Ecuador, según el Geoportal de Visitas Internas Turísticas (Mintur, 2017) se registraron en el Ecuador 115 millones de visitas turísticas en el Ecuador durante el año 2017, se considera un turista a aquella persona que se desplaza a un cantón diferente del habitual de residencia por motivos turísticos y realiza una pernoctación, en el 2017. Los 4 cantones de la zona, incluyendo Sucre por la ciudad de Bahía de Caráquez, solo representa el 0.79\% de las visitas a nivel nacional (Figura 14).

\section{Modalidades de turismo}

Predomina el turismo de sol y playa, la escasa diversificación y conocimiento del público en general limita el acceso a los demás atractivos turísticos de la región. Es decir, el turismo nacional e internacional va a la zona buscando sol y playa principalmente, pero existen actividades adicionales que se pueden efectuar como, por ejemplo, la presencia de yates y veleros, que, aunque son privados, en Bahía de Caráquez hacen recorridos fuera del estuario de Bahía especialmente para la recreación personal de jubilados 
extranjeros que viven en Bahía de Caráquez y que utilizan la zona sur del área de estudio. Existe interés en desarrollar turismo de observación de ballenas por parte de las comunidades locales, pero necesitan capacitación e inversión para poder ofertar el servicio de manera formal (figura 15).
Hay también una importante oportunidad para el turismo de naturaleza: existen 3 áreas protegidas cercanas, bosque seco y bosque húmedo en buen estado.

Tabla 5. Importancia de las playas turísticas de la zona de estudio. Fuente: Mintur (2004). Table 5. Importance of tourist beaches in the study area. Source: Mintur (2004).

\begin{tabular}{|l|l|l|}
\hline \multicolumn{1}{|c|}{ I (Local) } & \multicolumn{1}{|c|}{ II (Regional) } & III (Internacional) \\
\hline Playa Carrizal & Playa Pedernales & Playa de Canoa \\
\hline Playa Tasaste & $\begin{array}{l}\text { Playa Cabeza de Baca, Arrastradero, Zurrones, El Corcovado, } \\
\text { Juananu, Coco Solo y Casa blanca }\end{array}$ & \\
\hline Playa El Matal & Playa Punta Napo & \\
\hline Playa la División & Playa de Briceńo & \\
\hline Playa boca del Río Jama & Playa de Tabuga & \\
\hline Playa Camarones & Playa Punta Prieta & \\
\hline Playa la Chorrera & Playa Don Juan & \\
\hline Playa la Cabuya & Playa Punta Ballena & \\
\hline Playa Punta Palmar & Playa Cojimies & \\
\hline Playa Coaque & Playa San Vicente & \\
\hline Playa Punta Los Frailes & Playa Cabo Pasado & \\
\hline Playa los Perales & & \\
\hline
\end{tabular}
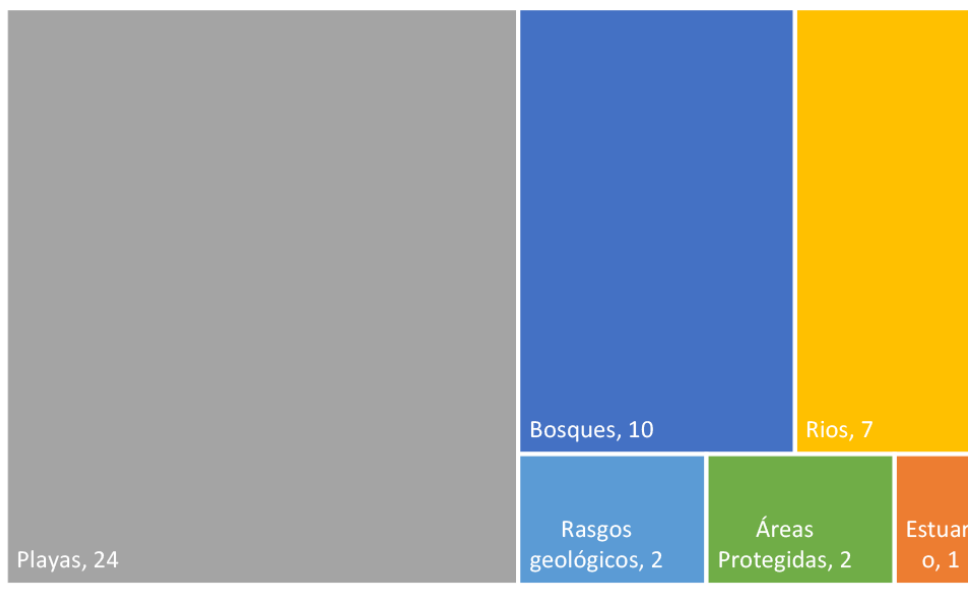

Figura 13. Tipos de atractivos turísticos naturales de la zona. Fuente: MINTUR (2004).

Figure 13. Types of natural tourist attractions in the area. Source: MINTUR (2004). 


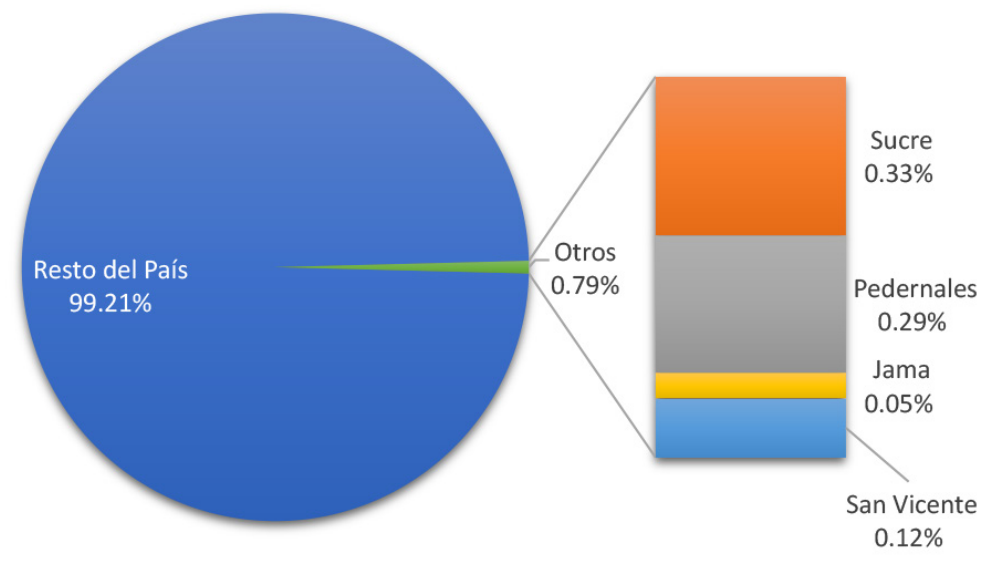

Figura 14. Relación de visitantes turistas en los cantones del área de estudio i ncluyendo el cantón Sucre. Fuente: MINTUR (2018).

Figure 14. Relation of tourist visitors in the cantons of the study area including the Sucre canton. Source: MINTUR (2018).

\section{Asuntos de manejo identificados}

- Falta de ordenamiento de las playas del sector: conflictos entre las actividades de pesca artesanal, laboratorios de larvas y turismo.

- Prestadores de servicios turísticos provenientes de otras localidades, llegan durante los feriados nacionales y los municipios no tienen la capacidad de gestionar su afluencia.

- Iniciativas para la observación de ballenas en Pedernales, Jama y San Vicente, realizada de manera artesanal y sin cumplir con los requisitos del acuerdo interministerial 2014-004 (que regula la observación de ballenas y delfines).

Se mencionó también un hecho importante, que, debido a la situación de inseguridad en la zona de Esmeraldas, los operadores de observación de ballenas establecieron sucursales de estas operadoras en Pedernales para ofertar el servicio en esta temporada 2017 (Director de Turismo, Gobierno Autónomo Descentralizado [GAD] de Pedernales, comm pers.), esto ha permitido mantener un flujo de turistas que fue afectado por el terremoto del 2016.

Existen importantes oportunidades para diversificar la oferta turística en el sitio más allá de turismo de sol y playa, el turismo cultural, de aventuras y/o gastronómico que permitirían mantener un flujo constante de turistas todo el año.

\section{Tráfico marítimo}

El uso del espacio marítimo para el tránsito de embarcaciones en la zona es considerable. En julio 2013, 652 embarcaciones usaron el área, tanto para pesca como para tránsito, en base a los registros de la Dirección Nacional de Espacios Acuático (Dirnea) del sistema VMS.

Las embarcaciones con mayor presencia fueron las de pesca artesanal, algo inusual porque las embarcaciones artesanales (conocidas como "fibras") no tienen la obligación a llevar el sistema VMS, y generalmente valores de tonelaje de alrededor de 1 tonelada de registro bruto (TRB), lo que es consistente con las embarcaciones artesanales de fibra de vidrio, siguiéndole los barcos pesqueros (no especifica de que tipo). En total 571 embarcaciones (88\%) que tienen como objetivo la pesca estuvieron registradas dentro del área de estudio (tabla 6, figura 16).

Las embarcaciones dedicadas a carga y pasaje fueron 66 y de turismo 11, el resto no tenía identifica- 

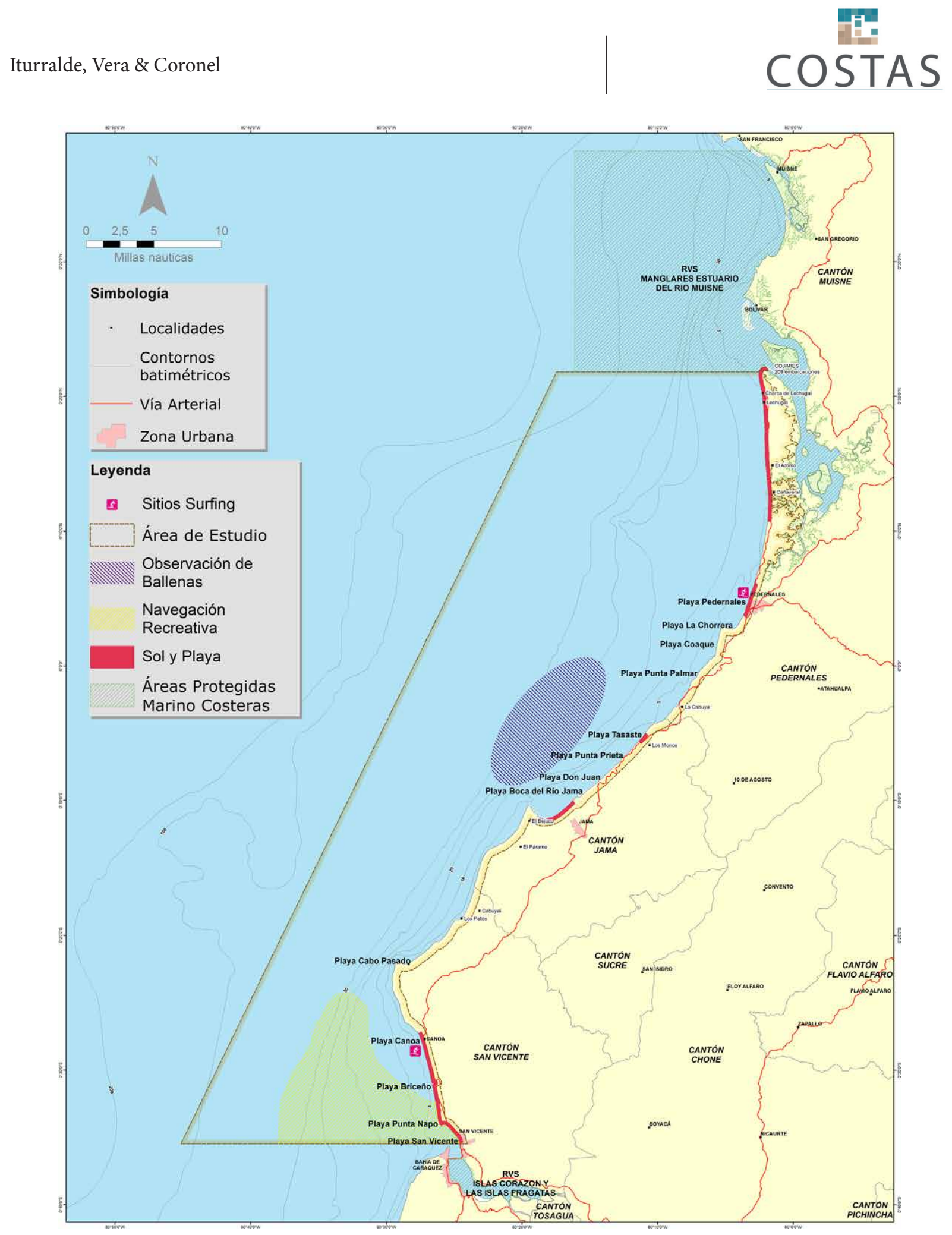

Figura 15. Uso: Turismo en la zona de estudio.

Figure 15. Use: Tourism in the study region. 
Tabla 6. Presencia de embarcaciones que cuentan con VMS durante julio 2013, elaborado en base a DIRNEA (2014).

Table 6. Presence of vessels that have VMS during July 2013, prepared based on DIRNEA (2014).

\begin{tabular}{|c|c|c|}
\hline & Tipo & Número \\
\hline \multirow{8}{*}{ Pesca } & Atunero & 13 \\
\hline & Balandra & 1 \\
\hline & Barco pesquero & 82 \\
\hline & Fibras (Canoa) & 8 \\
\hline & Long Line & 2 \\
\hline & Pesca artesanal & 446 \\
\hline & Pesca Merluza & 8 \\
\hline & Sardinero & 11 \\
\hline \multirow{4}{*}{ Carga } & Buque de Carga General & 1 \\
\hline & Carga y pasaje & 10 \\
\hline & Petrolero & 3 \\
\hline & Empujador/Remolcador & 6 \\
\hline \multirow[b]{2}{*}{ Transporte } & Buque de pasaje $<12$ pasajeros & 32 \\
\hline & $\begin{array}{l}\text { Buque de pasaje entre } 12 \text { y } 35 \\
\text { pasajeros }\end{array}$ & 14 \\
\hline \multirow{3}{*}{ Turismo } & Velero & 1 \\
\hline & Yate & 10 \\
\hline & No especificada & 4 \\
\hline
\end{tabular}

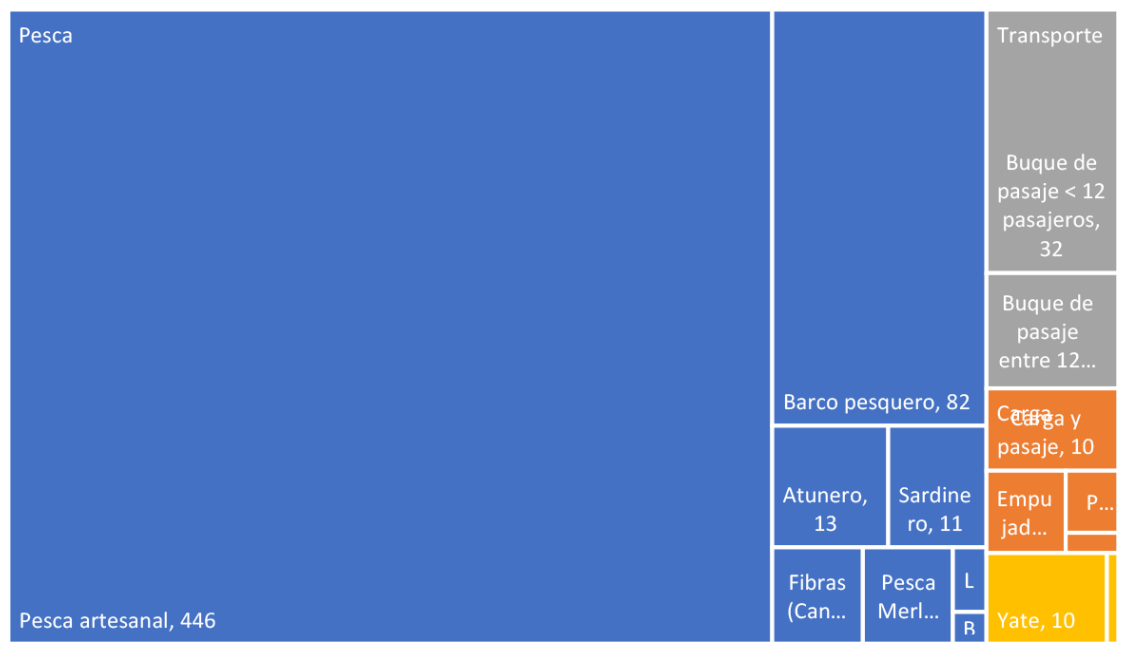

Figura 16. Proporción de la presencia de embarcaciones que cuentan con VMS durante julio 2013. Fuente: elaborado en base a DIRNEA (2014).

Figure 16. Proportion of the presence of vessels that have VMS during July 2013. Source: prepared based on DIRNEA (2014). 
ción. En base a la información disponible se observa que hay una ruta de transporte de hidrocarburos en el borde externo del área marina, así como transporte de carga nacional e internacional (figura 17).

\section{Concesiones mineras}

Dentro del área de estudio, hay 4 concesiones mineras. 3 de minería artesanal y 1 de libre aprovechamiento, principalmente en el cantón Jama. Pero también hay evidencia de extracción de arena en Cabo Pasado y Punta Napo (figura 18). Los municipios reconocen que es un gran problema, pero no tienen la capacidad para enfrentarlo. La extracción de arena puede impactar negativamente las zonas de anidación y disponibilidad de hábitat para tortugas marinas que anida en la zona.

\section{Conservación}

Dentro del área no se encuentran áreas protegidas, pero sí áreas consideradas como vacíos de la conservación marina de prioridad media y baja. Se destaca la presencia de una herramienta de conservación importante, la milla náutica de protección de los recursos bioacuáticos, que representa $253 \mathrm{~km}^{2}$ (7.2\% del área de estudio).

También se considera a los espacios que pescadores artesanales califican como importantes para conservar (zonas de pesca y reproducción), así como las zonas reportadas anecdóticamente como de anidación de tortugas marinas (figura 19).

\section{Usos temporales}

Actualmente existe una serie de normas pesqueras que establecen vedas temporales de los recursos bioacuáticos a nivel nacional (tabla 7), las vedas son importantes herramientas de manejo, aunque no las únicas, a las que se añaden las tallas mínimas, cuotas de captura, restricciones espaciales, restricción de artes de pesca, entre otros. En el área de estudio por los recursos que se aprovechan hay una serie de normas que hay que tener en consideración.

Adicionalmente tenemos, la presencia de ciertas especies de interés para la conservación que son más vulnerables de forma estacional ya sea por sus hábitos migratorios o por sus ciclos de vida, como son las ballenas jorobadas y las tortugas marinas, y es en estas fechas donde se pueden producir más interacciones con actividades y operaciones pesqueras y el uso de playas para recreación y turismo.

En este caso, la mortalidad de tortugas marinas y ballenas jorobadas aumenta a nivel nacional en los meses de junio a octubre, en muchos casos por interacción con pesquerías (Alava et al., 2005a, 2005b, 2012, 2019). Esto también nos ayuda a identificar que, en las playas de anidación de tortugas marinas, en los meses de julio a marzo, hay que tener consideraciones especiales para asegurar anidaciones exitosas.

\section{Conflictos identificados en los talleres y en las visitas de campo}

En el taller de octubre del 2018 realizado en El Matal, Cantón Jama, los participantes identificaran en una matriz los conflictos existentes, los cuales fueron graficados en el taller. Esta identificación se realizó a través del mapeo participativo realizado en los talleres, donde los diferentes actores presentes dibujaban en grandes mapas los usos que realizaban y los conflictos que se identificaban, esa información fue validada a través de la literatura existente y los recorridos que se hicieron en el campo (figura 20).

A continuación, se describe cada uno de los conflictos ambientales identificados:

- Pescadores artesanales e industriales: Pescadores industriales ingresan dentro de la zona de reserva de pesca artesanal, lo que ha obligado a los pescadores a buscar zonas de pesca más allá de las $25 \mathrm{mn}$. 


\section{물 \\ COSTAS}

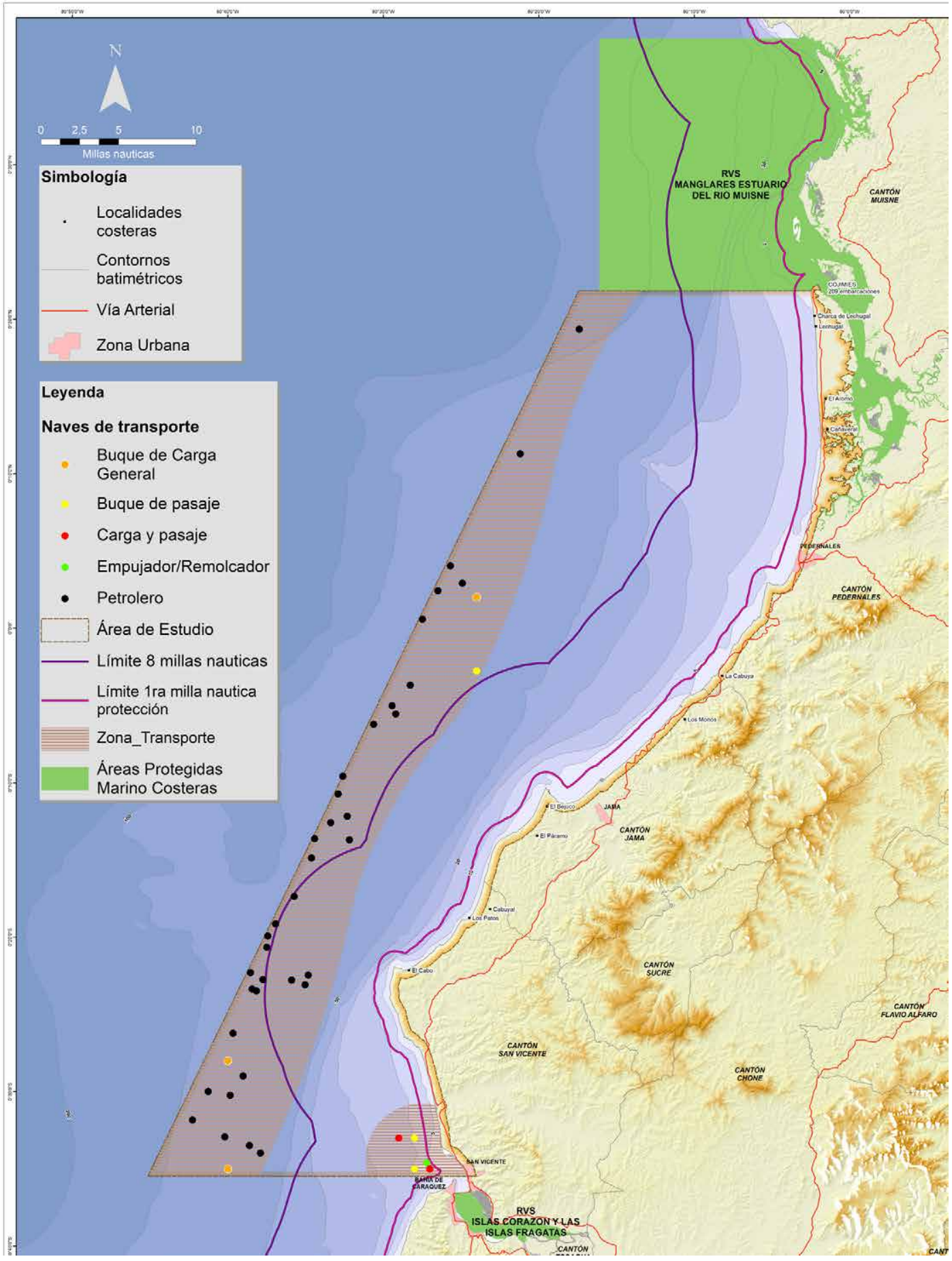

Figura 17. Uso: Transporte marítimo.

Figure 17. Use: Maritime transport. 
Iturralde, Vera \& Coronel

COSTAS

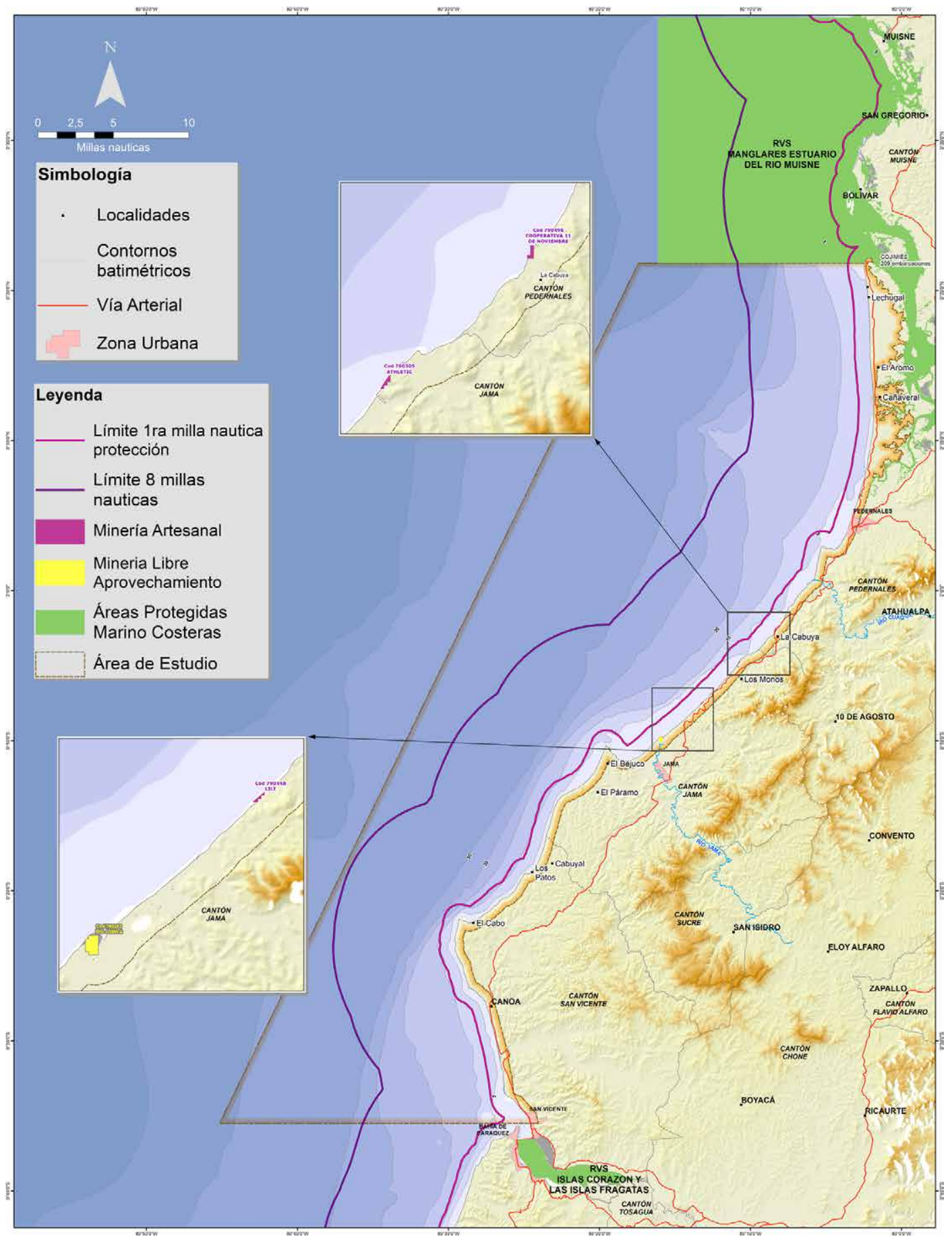

Figura 18. Uso: Concesiones mineras.

Figure 18. Use: Mining concessions. 


\section{뭄 \\ COSTAS}

Revista Costas, Vol. Esp. 2, 2021

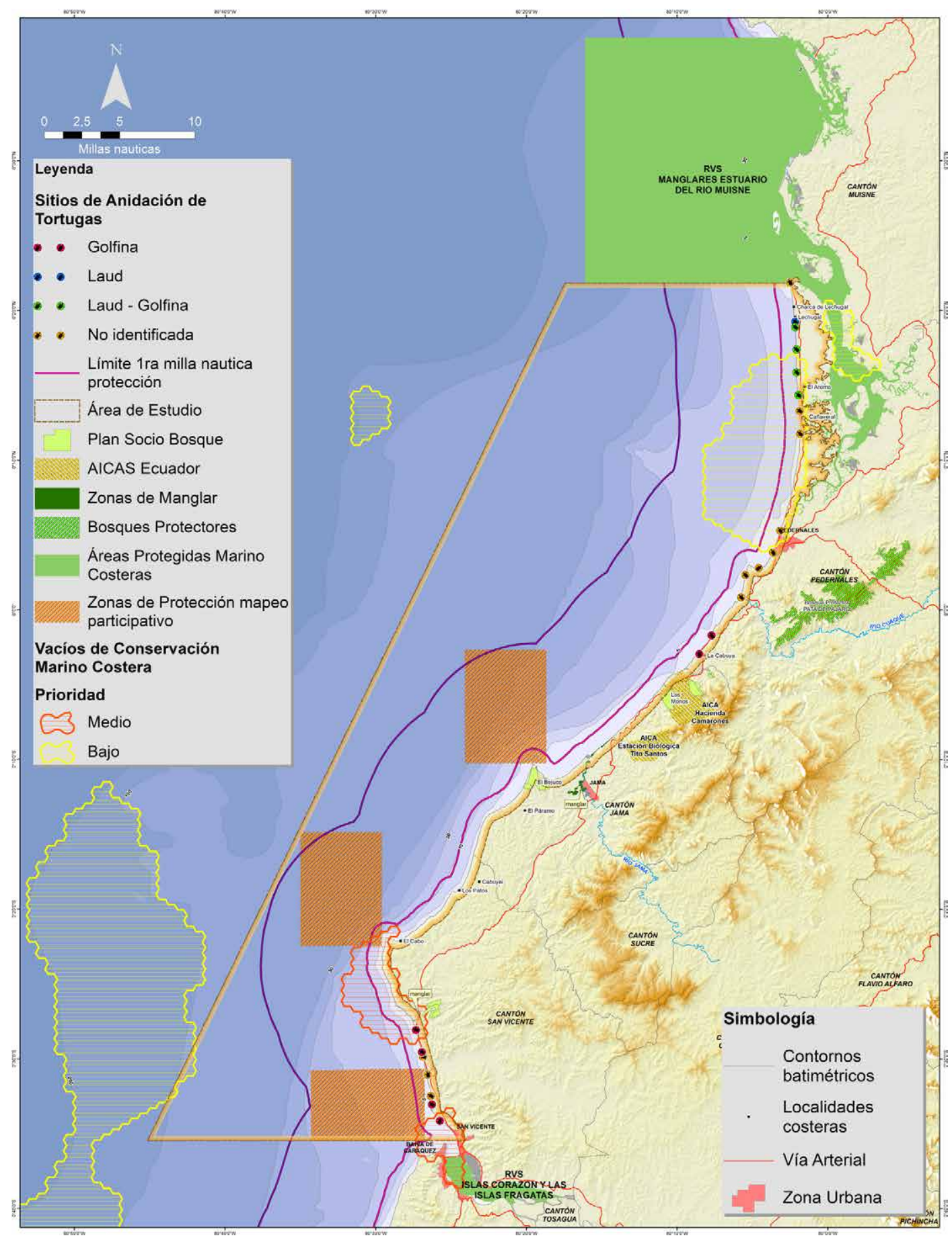

Figura 19. Uso: Conservación.

Figure 19. Use: Conservation. 
Tabla 7. Uso o presencia temporal de los principales recursos biológicos que se encuentran en la zona. Fuente: MPCEIP (2019).

Table 7. Use or temporary presence of the main biological resources found in the area. Source: MPCEIP (2019).

\begin{tabular}{|c|c|c|c|c|c|c|c|c|c|c|c|c|}
\hline \multirow[b]{2}{*}{ Especie } & \multicolumn{12}{|c|}{ Mes } \\
\hline & 1 & 2 & 3 & 4 & 5 & 6 & 7 & 8 & 9 & 10 & 11 & 12 \\
\hline \multicolumn{13}{|l|}{ Vedas } \\
\hline \multicolumn{13}{|l|}{ Langosta } \\
\hline \multicolumn{13}{|c|}{ Pelágicos pequeños } \\
\hline \multicolumn{13}{|l|}{ Dorado } \\
\hline \multicolumn{13}{|l|}{ Merluza } \\
\hline \multicolumn{13}{|l|}{ Pulpo } \\
\hline \multicolumn{13}{|l|}{ Camarón blanco } \\
\hline \multicolumn{13}{|c|}{ Presencia Estacional } \\
\hline \multicolumn{13}{|l|}{ Ballena Jorobada } \\
\hline \multicolumn{13}{|l|}{$\begin{array}{l}\text { Tortuga golfina } \\
\text { (anidación) }\end{array}$} \\
\hline $\begin{array}{l}\text { Tortuga Verde } \\
\text { (anidación) }\end{array}$ & & & & & & & & & & & & \\
\hline
\end{tabular}

- Comunidad y acuicultura de agua dulce: Competencia por acceso al recurso agua para consumo humano.

- Pescadores artesanales e independientes: Pescadores no agremiados no cumplen con las normas.

- Turismo sol y playa y pescadores artesanales: competencia por el uso de las playas, realizan actividades de eviscerado y desechos sólidos que afectan a los turistas.

- Turismo sol y playa y laboratorios de larvas: competencia por el uso de playas.

- Municipios y prestadores de servicios externos: difíciles de ordenar por ser de otras comunidades.

- Comunidades y propietarios de terrenos frente a la playa: no permiten el acceso a las playas públicas porque no hay accesos públicos.

- Hay un conflicto estacional entre los pescadores artesanales y la migración de ballenas jorobadas.

\section{Conflictos futuros identificados}

\section{en los talleres y en las visitas de campo}

En el mismo taller de octubre (2018), se pidió a los participantes que identificaran en una matriz los conflictos futuros (figura 21), los cuales fueron graficados en una plenaria.

Esta identificación, al igual que en el caso anterior, se realizó a través del mapeo participativo, donde los diferentes actores presentes dibujaban en grandes mapas los usos que realizaban y los conflictos que se identificaban, esa información fue validada a través de la literatura existente y los recorridos que se hicieron en el campo:

- Maricultura con Pescadores artesanales e industriales: El posible uso de espacio marino para temas de maricultura podría causar conflictos con el sector pesquero. 


\section{Fin \\ COSTAS}

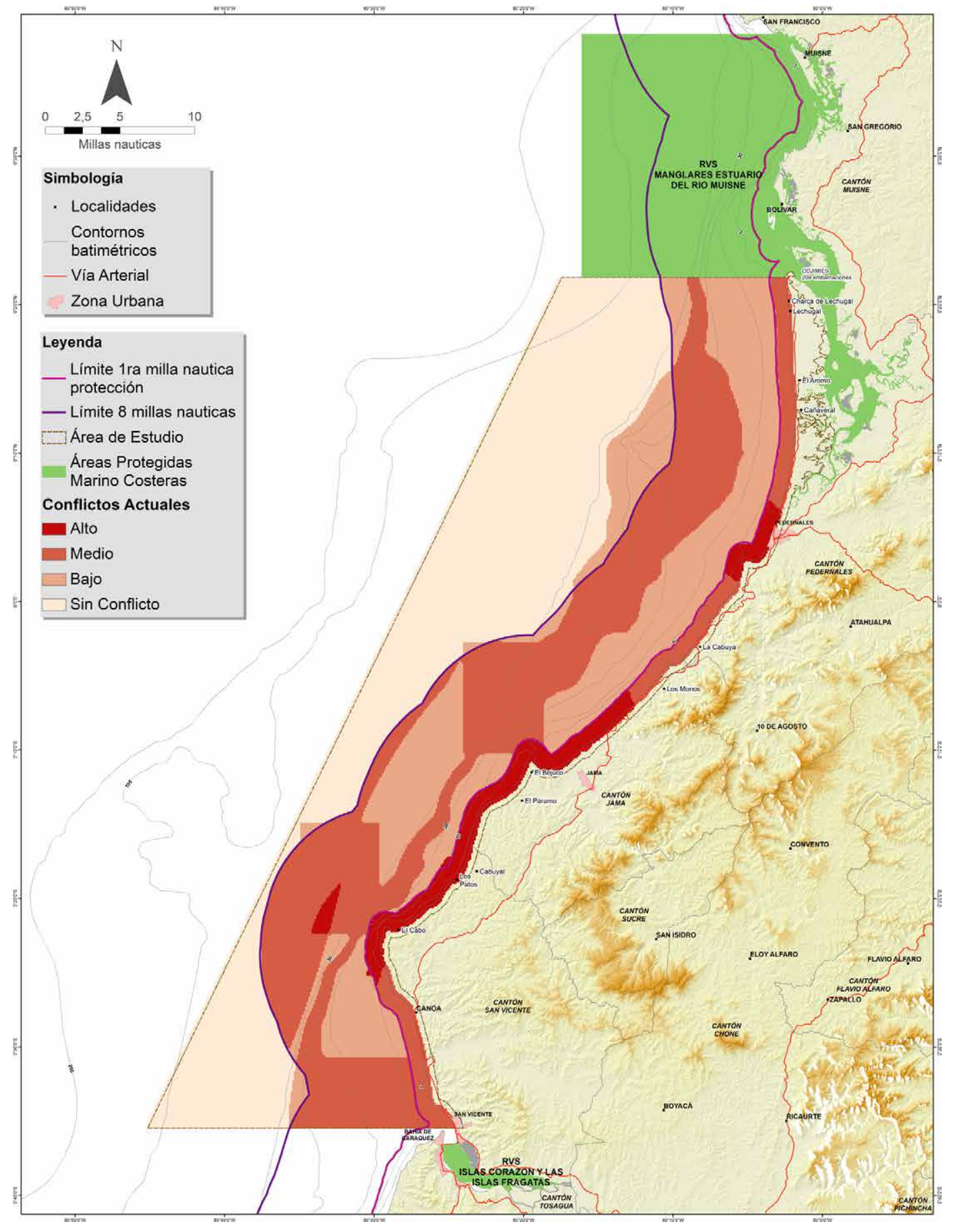

Figura 20. Conflictividad actual en la zona de Manabí Norte. Fuente: elaboración propia.

Figure 20. Current conflict in the Manabí Norte area. Source: own elaboration. 
Iturralde, Vera \& Coronel

COSTAS

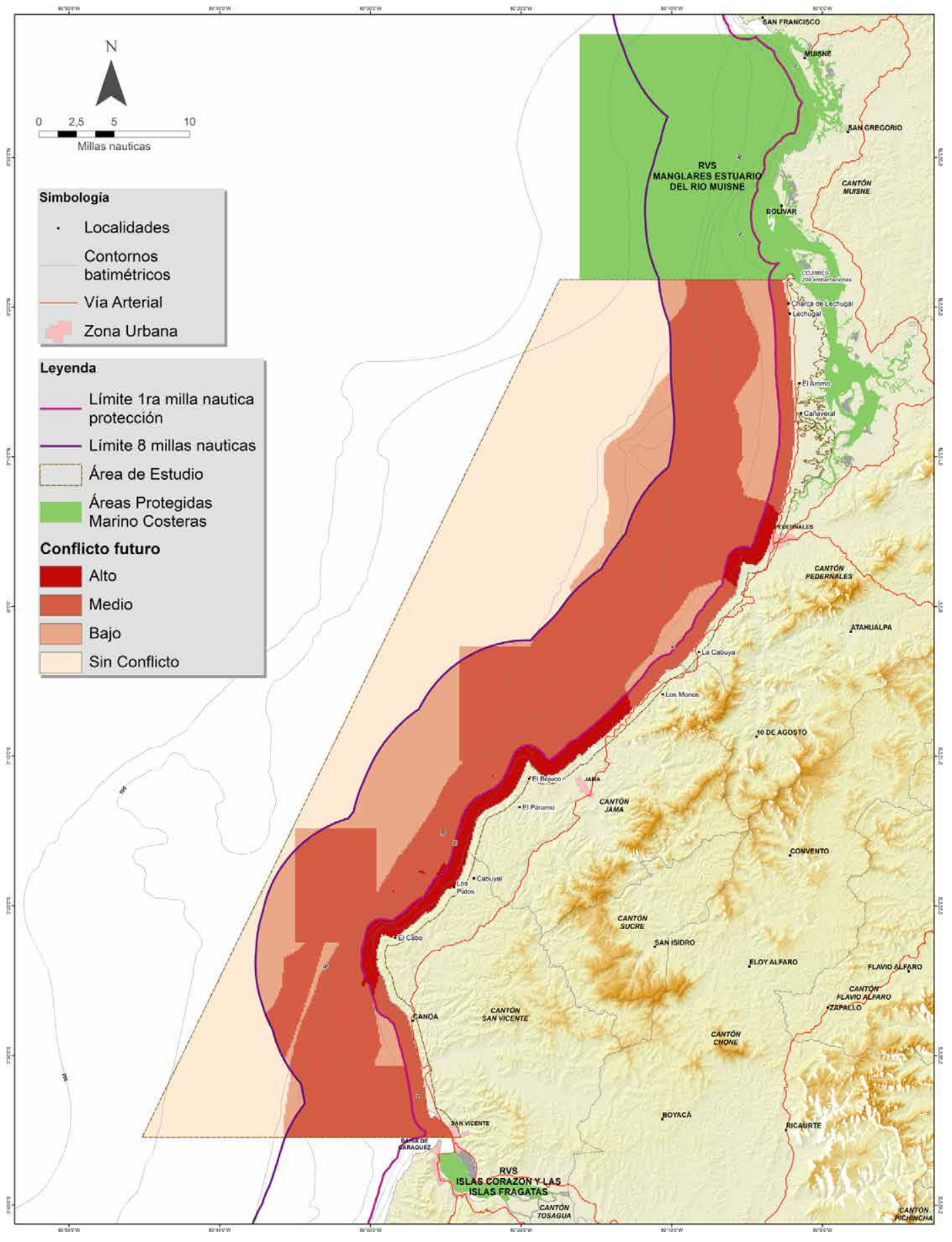

Figura 21. Conflictividad futura en la zona de Manabí Norte. Fuente: elaboración propia.

Figure 21. Future conflict in the Manabí Norte area. Source: own elaboration. 


\section{ris \\ COSTAS}

- Maricultura con rutas de migración de ballenas: El posible uso de espacio marino para temas de maricultura podría causar interacción con el turismo de observación de ballenas jorobadas.

\section{Priorización de los conflictos identificados}

Como resultados se identificaron y delimitaron las zonas con mayor conflictividad por el uso actual y futuro (Coronel, 2018).

\section{Prefactibilidad}

Basado en los criterios para definir la prefactibilidad de la zona (tabla 8) se encontró que los valores más altos son capacidad técnica, apoyo social y nivel de conflictividad. El total calculado es 43 puntos, lo que se considera Alto. Esto indica que se puede continuar hacia la siguiente etapa de factibilidad (considerada como la fase de diseño del plan de ordenamiento) para la implementación de un proceso de ordenamiento marino y costero.

Tabla 8. Calificación de criterios de prefactibilidad para el ordenamiento espacial marino en la zona de Manabí Norte (este documento).

Table 8. Qualification of pre-feasibility criteria for marine spatial planning in the Manabí Norte area (this document).

\begin{tabular}{|c|c|c|}
\hline Criterios & Justificación & Puntaje \\
\hline Gobernabilidad: & $\begin{array}{l}\text { La coordinación de actividades entre instituciones para solucionar problemas comunes es } \\
\text { deficiente, los problemas tienden a agravarse por falta de atención oportuna. } \\
\text { Este fue un clamor general de los asistentes al taller y fue reconocido por algunas de las } \\
\text { autoridades presentes. }\end{array}$ & 3 \\
\hline Social: & $\begin{array}{l}\text { El apoyo de las comunidades hacia la iniciativa es alto, aunque reconocen que ellos son los } \\
\text { primeros en reconocer que incumplen las leyes y que necesitan capacitación, pero también } \\
\text { reconoces que es una necesidad el ordenamiento y el cumplimiento de las normas para el } \\
\text { buen uso de los recursos marinos y costeros. }\end{array}$ & 8 \\
\hline Capacidad Técnica & $\begin{array}{l}\text { Existe actualmente en el país una buena capacidad técnica para realizar procesos de orde- } \\
\text { namiento marino costeros. Esto producto de las diferentes iniciativas de la cooperación } \\
\text { internacional, así como personal capacitado en el PMRC y administradores de áreas } \\
\text { protegidas. }\end{array}$ & 8 \\
\hline Aspectos Legales & $\begin{array}{l}\text { Existen algunas leyes y normas que propician el ordenamiento espacial marino y costero, } \\
\text { pero con marcados conflictos entre las mismas y muchos vacíos. Actualmente, se cuenta } \\
\text { con el marco de políticas marinas y costeras, el Código Orgánico Ambiental, el COOTAD } \\
\text { y la Constitución del Ecuador, no se cuenta con normativa específica para el ordenamiento } \\
\text { marino y costero. }\end{array}$ & 3 \\
\hline $\begin{array}{l}\text { Importancia } \\
\text { económica }\end{array}$ & $\begin{array}{l}\text { Hay un mediano a alto aporte de beneficios hacia la comunidad. Importancia a nivel } \\
\text { provincial. } \\
\text { Las comunidades de la zona dependen fuertemente de los recursos marinos y costeros, } \\
\text { algunas de las actividades económicas que se realizan (acuacultura y pesca) son de interés } \\
\text { para la exportación. }\end{array}$ & 8 \\
\hline $\begin{array}{l}\text { Importancia } \\
\text { Ambiental. }\end{array}$ & $\begin{array}{l}\text { La zona cuenta con una importancia ambiental, ecológica a nivel regional, por la presencia } \\
\text { de especies migratorias y especies de interés para la conservación, así como la importancia } \\
\text { de los servicios ambientales que ofrece a las comunidades costeras. }\end{array}$ & 5 \\
\hline $\begin{array}{l}\text { Nivel } \\
\text { de conflictividad }\end{array}$ & $\begin{array}{l}\text { Hay un nivel de conflictividad mediano, con muchos actores, pero es posible resolverlos a } \\
\text { través del diálogo. }\end{array}$ & 8 \\
\hline
\end{tabular}




\section{Propuesta de Manejo}

Como resultados se definió con la comunidad local y autoridades presentes una visión de desarrollo y objetivos básicos de manejo para el ordenamiento de las actividades a realizarse. Los objetivos fueron elaborados en base a las discusiones realizadas en los talleres y la revisión de la literatura existente.

Visión: La zona marina y costera de Manabí Norte se convertirá en un espacio planificado, ordenado, seguro, donde se respetan las normas, se conserve la biodiversidad marina y costera de la zona y los servicios ecosistémicos que nos brinda en la búsqueda del desarrollo sustentable y armónico de las comunidades que dependen de la zona y los actores que la aprovechan.

\section{Objetivos:}

- Respetar el ordenamiento vigente de actividades en la zona.

- Asegurar la provisión de servicios ambientales que nos provee la zona, especialmente una pesca sustentable.

- Buscar la participación efectiva de las comunidades para el manejo y resolución de conflictos.

Además, se desarrolló una posible propuesta de manejo, basada en tres escenarios identificados ( $\mathrm{Sin}$ intervención, Manejo Básico, Manejo Optimo, ver tabla 9). Sin embargo, la orientación está dirigida a llegar a un esquema de manejo óptimo bajo las siguientes condiciones:

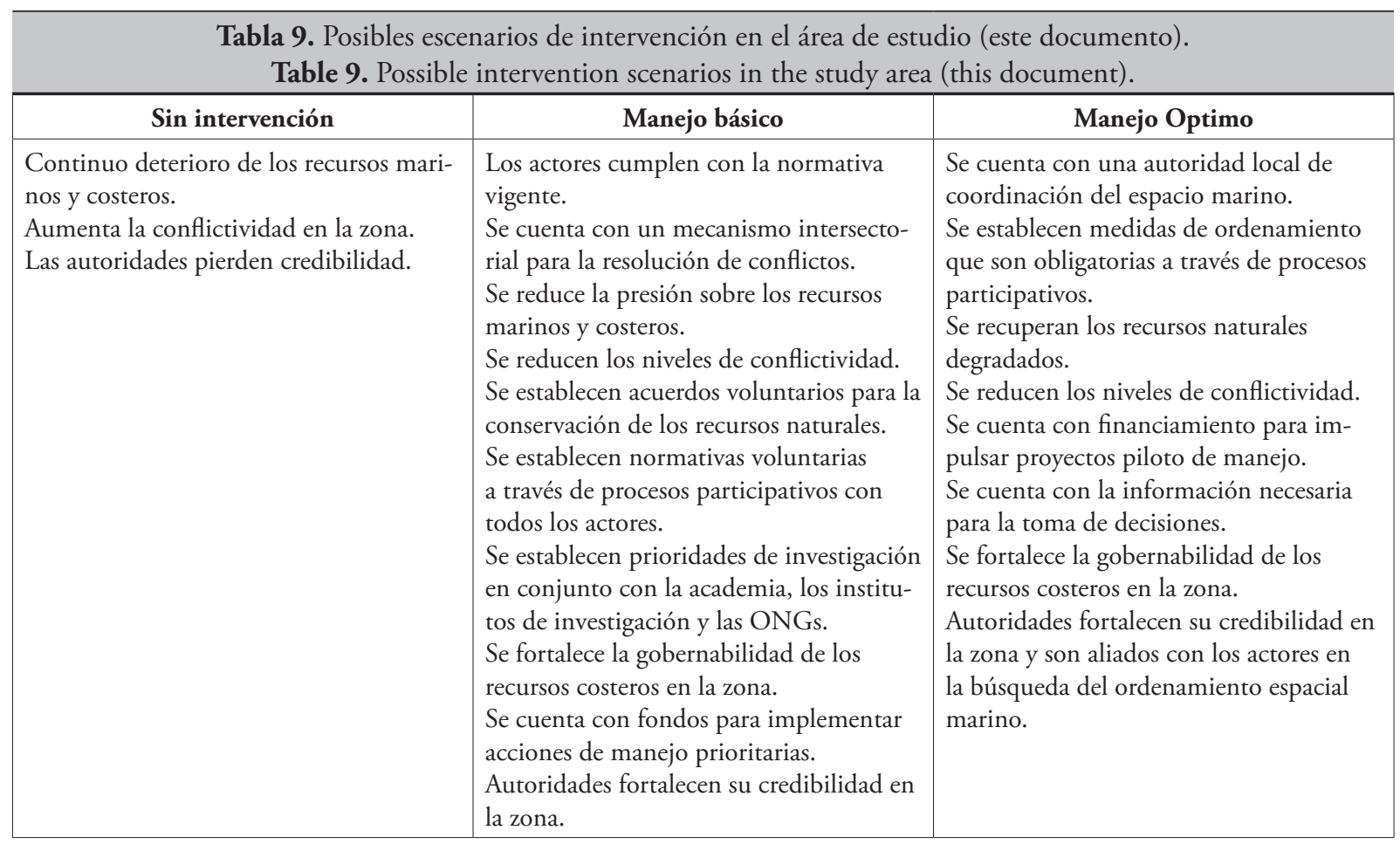




\section{rag \\ COSTAS}

- Se establece un comité local para el ordenamiento de la zona marina y costera, con el objetivo de cumplir la normativa actual del ordenamiento pesquero y manejo de playas bajo los lineamientos nacionales. Otro rol del comité incluye el identificar experiencias piloto que permitan resolver situaciones de conflicto de baja escala.

- Se cuenta con un equipo mínimo dedicado a impulsar el proceso a través de la coordinación, resolución de conflictos y asistencia técnica de los GAD. Se establecen playas modelos para su ordenamiento en trabajo conjunto con los municipios. Se cuenta con un capital pequeño para implementar las experiencias piloto y el compromiso de las instituciones y actores de cumplir con los acuerdos alcanzados

- Se cuenta con un plan de ordenamiento desarrollado de manera participativa que sea adaptativo y con metas e indicadores para verificar su cumplimiento y avances.

- Se refuerza el cumplimiento de la normativa vigente y la imposición de sanciones cuando sea al caso; donde no hay normativa vigente, se buscarán acuerdos de uso a través de procesos de negociación participativa.

Pero este es un modelo escalable. En una primera etapa se puede buscar la implementación del esquema básico de manejo, contando necesariamente con fondos para implementar algunas acciones mínimas de manejo, acciones que, aunque pequeñas, son un buen inicio para afianzar el ordenamiento, considerando que se tiene un gran apoyo local.

\section{Recomendaciones para el manejo}

En base a experiencias previas, por ejemplo, el PMRC, y las discusiones en los talleres (donde los actores también realizaron recomendaciones para el manejo del área), se identificó una serie de recomendaciones, las cuales deben de ser analizadas en posteriores procesos de construcción junto con una propuesta inicial de ordenamiento, donde se aplica la normativa actual y se busca lograr acuerdos de conservación entre usuarios, considerando la variación temporal y espacial (figura 22).

\section{Espacio costero}

- Creación de un Comité Local como un espacio para la coordinación interinstitucional de construcción de acuerdos y resolución de conflictos, que cuente con personal dedicado para la coordinación y apoyo técnico.

- Microzonificar las playas de importancia para la región, para poder ofertar un mejor producto turístico a los visitantes, incluyendo la diversificación de los atractivos turísticos para brindar una mejor experiencia, definiendo dentro de las playas usos incompatibles además de equiparlas con la infraestructura necesaria y la señalización adecuada.

- Los gobiernos Municipales deben buscar acuerdos necesarios para asegurar el acceso público a las playas, incluyendo, como requisito para la aprobación de los proyectos de construcción, dejar una superficie adecuada como área de servidumbre municipal.

- Se debe buscar articular con otras iniciativas de conservación de la zona como, por ejemplo, la Cordillera del Bálsamo al sur del área de estudio.

- Desarrollar una estrategia de promoción turística; una vez que se comience a construir productos turísticos de calidad, éstos se deben promocionar adecuadamente para la atracción de un mejor tipo de turista.

- Articular, a nivel de gobierno municipal, el ordenamiento del territorio terrestre con el ordenamiento costero para que haya compatibilidad entre los diferentes instrumentos de planificación y manejo (ordenanzas). 


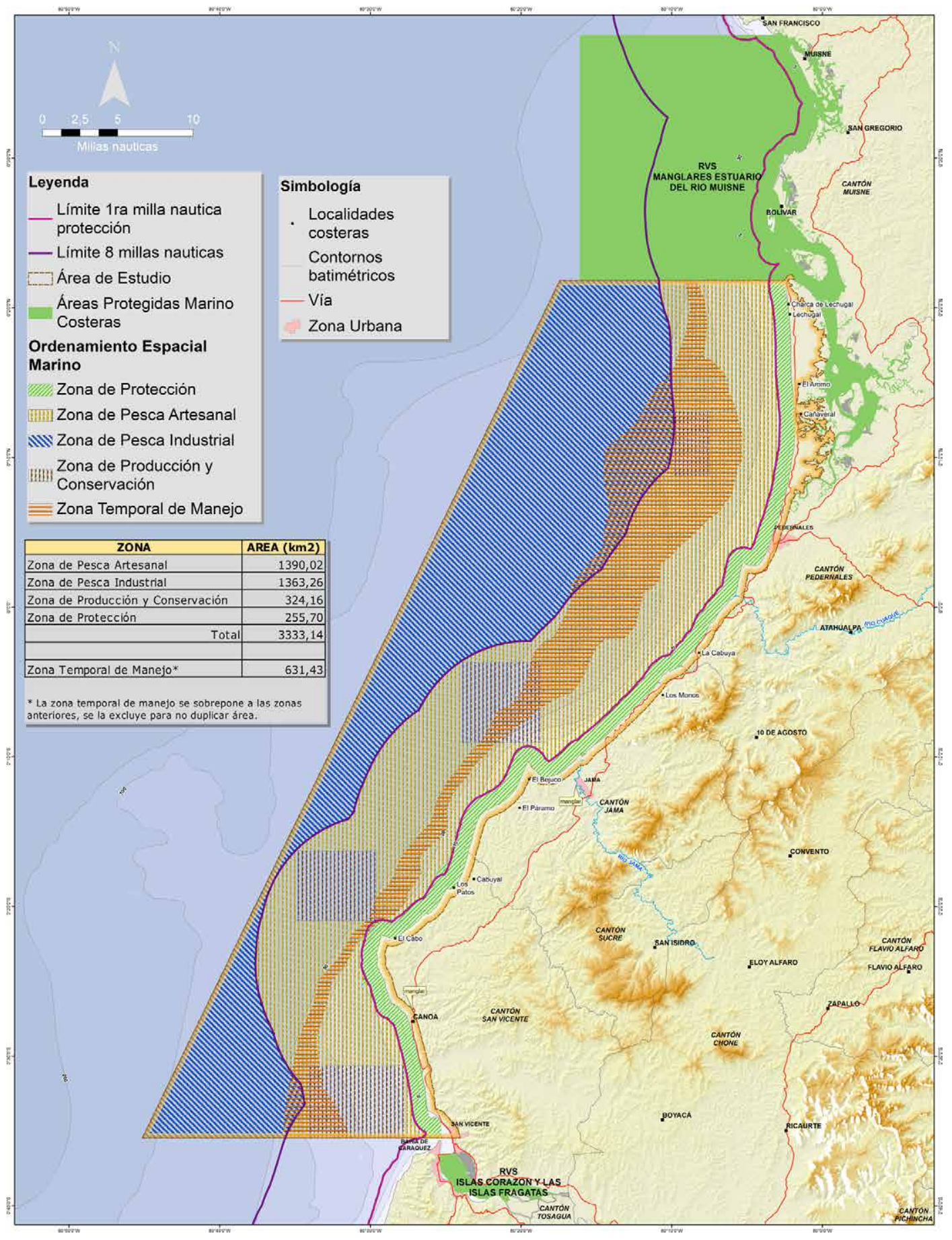

Figura 22. Propuesta de ordenamiento espacial marino en la zona de Manabí Norte.

Figure 22. Proposal for marine spatial planning in the Manabí Norte area. 


\section{rig \\ COSTAS}

- Realizar una evaluación del cumplimiento de la normativa ambiental de laboratorios de larvas y granjas acuícolas.

- Identificar los sitios críticos para la extracción ilegal de arena e implementar una estrategia para resolver la problemática (ej. cámaras de seguridad).

- Identificar y considerar dentro del ordenamiento costero los sitos de anidación de tortugas marinas.

- Promover la educación ambiental para el buen uso de los recursos marinos y costeros a todo nivel con la colaboración de la autoridad educativa y la autoridad ambiental.

- Promover la asociatividad de las organizaciones pesqueras artesanales a través de la capacitación, acceso a créditos blandos, fortalecimiento institucional, etc.

\section{Espacio marino}

- Articular el ordenamiento del espacio marino de la zona con la zonificación de las áreas protegidas cercanas, especialmente con el Refugio de Vida Silvestre Manglares del Río Muisne que son colindantes de forma directa.

- Promover con la autoridad marítima la creación de rutas de navegación fuera de las aguas interiores, especialmente en el caso de transporte de hidrocarburos para evitar conflictos con otros usuarios y evitar el riesgo de accidentes.

\section{Discusión}

El ordenamiento espacial marino y costero, si se implementa de forma adecuada, permite obtener beneficios ambientales, sociales y económicos (Ehlers \& Douvere, 2009; WWC, 2014), no busca la conservación por sí misma, aunque este sector también se beneficia, sino que busca la armonía entre los diferentes
- Impulsar con la autoridad pesquera y la Capitanía de Puerto de Bahía el cumplimiento del ordenamiento pesquero vigente, para lo cual se debe utilizar las herramientas tecnológicas disponibles (monitoreo VMS).

- Desarrollar una estrategia para preservar la seguridad de la vida humana en el mar y la prevención de delitos, que incluya al sector pesquero artesanal y que provea de los medios de comunicación y protocolos adecuados para resolver la problemática de inseguridad en la zona marina.

- Durante la temporada de ballenas (julio a septiembre) y durante la época de reproducción de tortugas marinas impulsar el cambio de artes de pesca dentro de las 5 millas para evitar el uso de trasmallos que causa interacción con estas especies de interés para la conservación y pérdidas económicas para los pescadores.

- Aunque no hay al momento iniciativas de maricultura a ser implementadas en la zona, hay una experiencia piloto en el estuario del Río Chone implementada por una universidad, si en el futuro se desarrolla esta actividad se debe considerar varios criterios para su implementación, como por ejemplo en el caso de implementación de cultivo de peces en jaula: la seguridad, no interrumpir la libre navegación y estrictos controles ambientales para no degradar los hábitats marinos. sectores económicos, sociales y ambientales con la finalidad de brindar beneficios justos para todos los involucrados sin afectar los servicios ecosistémicos que nos presta (Santos et al., 2019). Tanto la Planificación Espacial Marina como el Manejo Integrado de la Zona Costera se han identificado como impor- 


\section{re \\ COSTAS}

tantes herramientas para el cumplimiento de las metas de los Objetivos de Desarrollo Sustentable 14.1 y 14.2 (UN Environment, 2018).

Se han definido ciertos aspectos para lograr que los planes de ordenamientos espacial marinos sean exitosos (Ehler \& Douvere, 2010) como, por ejemplo: Autoridad, participación, basado en ecosistemas, integral, adaptativo y enfocado al futuro. Es necesario contar con una clara autoridad para su implementación. Y más recientemente se considera fortalecer un marco institucional y político, un adecuado monitoreo y evaluación e incluir la dimensión humana y datos socioeconómicos dentro del proceso de MSP (Frazáo Santos et al., 2018). Y aunque se recalca que no hay una receta única para implementar los planes de ordenamiento espacial (Collie et al., 2013), sí hay elementos esenciales para su éxito.

En la región, la implementación de esta herramienta está en sus primeros pasos, la iniciativa MSPGlobal que busca implementar el OEMC a nivel mundial resume el estado del proceso en varios países de América Latina: Ecuador, Colombia, Perú, Panamá y Argentina son los que tienen información en sus fichas nacionales, aunque hay más en preparación (MSPGlobal, 2020). De estos países, solo Ecuador se encuentra en estado aprobado; Argentina indica que está en fase de preplanificación; Colombia, se encuentra en proceso; Perú, en estado de pre-planificación sin embargo ha completado un proyecto piloto binacional sobre la Bahía del Golfo de Guayaquil; Panamá tiene un proyecto piloto en proceso la pre-planificación. En el caso de Perú, el proceso de manejo costero integrado reporta grandes avances en el tema de normativa, mientras que, en lo que respecta a la presencia de manejadores, recursos y participación pública, los avances han sido insuficientes (Barragán \& Lazo, 2018).

Específicamente en el Ecuador, se busca implementar un enfoque que involucre tanto el manejo costero como el marino en lo que se ha denominado
Ordenamiento Espacial Marino y Costero expresado a través del POEMC (Senplades, 2018), pero tanto su implementación como institucionalización todavía es débil. En el caso del manejo costero, a pesar de que forma parte del marco legal nacional desde la implementación del Código Orgánico del Ambiente (2018), su implementación no ha podido avanzar debido a una débil capacidad institucional (Pazmiño et al., 2018) y a la inestabilidad en los factores políticos y económicos (Mestanza et al., 2019), pese a que existen escasos recursos para el fortalecimiento de capacidades e implementación de proyectos piloto locales.

La zona de Manabí Norte basa su economía principalmente en tres actividades: la pesca, la acuicultura $y$, en menor grado, el turismo costero, que son muy importantes para las economías locales, especialmente de la población rural.

Hay inversiones crecientes para desarrollar el turismo costero, pero hay una serie adicional de atractivos turísticos que necesitan ser aprovechados para poder lograr un desarrollo importante en la región y no depender del turismo de sol y playa de feriados como única fuente de ingresos.

Existen algunos hallazgos importantes en cuanto a biodiversidad ya que este sitio reporta la presencia de arrecifes de poliquetos, hecho no muy común en la costa del Ecuador, así como una importante diversidad de macroinvertebrados (Bioelite, 2017), no así en el caso de peces marinos, y esto puede deberse a que los recursos marinos se encuentran sobre explotados (Bioelite, 2017), pero no se ha encontrado información que valide este hecho.

Además de ser es una zona de interés para la conservación de ballenas jorobadas y otras especies migratorias como tortugas y aves marinas. Hay registros anecdóticos de anidación de tortugas marinas, pero no hay un plan de monitoreo en marcha por lo que no se puede evaluar qué tan importante es en relación con el resto del país. En el caso de la ballena jorobada, 


\section{THA COSTAS}

esta zona se encuentra en su ruta migratoria hacia las aguas de Colombia y Costa Rica y de retorno hacia la Antártida, por lo que se han desarrollado algunas iniciativas incipientes de turismo local de avistamiento de ballenas.

Por estas razones la región tiene un importante valor nacional y regional y una gran capacidad de desarrollo, especialmente en las circunstancias actuales debido a la situación sanitaria y económica mundial. En este sentido, existe la posibilidad de impulsar el desarrollo económico sin considerar los impactos ambientales y sociales, privilegiando la visión a corto plazo, por lo que el imponer reglas claras y una visión regional participativa son procesos muy importantes en este momento, y es en este momento que es prioritario implementar acciones de ordenamiento espacial marino en conjunto con las comunidades locales.

Dentro del trabajo realizado se definieron algunos aspectos claves para iniciar el proceso de ordenamiento marino en el área:

\section{Uso del espacio actual}

Como ya se ha mencionado, al momento se ha identificado como usos principales en el área: las pesquerías (tanto industrial como artesanal), acuicultura, conservación, tráfico marino, turismo marino, migración de ballenas y desplazamiento y anidación de tortugas marinas. En muchos de los casos las zonas se superponen unas con otras, lo que indica que para que todas las actividades se cumplan sin interponerse se necesitaría $250 \%$ del espacio actual, es decir casi una vez y media más (figura 23, Tabla 10) del espacio actual para poder cubrir sin conflictos todas las actividades. Esto, obviamente, no es posible, por lo que se debe de trabajar de una forma planificada y ordenada para evitar los conflictos y problemas de manejo. Manejar de forma integral el territorio es el gran desafío, estableciendo objetivos comunes porque, aunque generalmente todos los sectores quieren lo mismo (uso sustentable de los recursos, equidad en el acceso a los mismos, desarrollo de oportunidades económicas y el respecto a su cultura), el estar de acuerdo en al camino a seguir para lograr estas aspiraciones es donde se presentan las dificultades.

Tabla 10. Uso del espacio marino en el área de estudio $\left(\mathrm{km}^{2}\right)$. Fuente: Coronel (2018). Table 10. Use of marine space in the study area $\left(\mathrm{km}^{2}\right)$. Source: Coronel (2018).

\begin{tabular}{|l|l|}
\hline \multicolumn{1}{|c|}{ Áreas identificadas } & \multicolumn{1}{|c|}{ Área $(\mathbf{k m} 2)$} \\
\hline Área estudio total & $3.518,0$ \\
\hline Área estudio marina & $3.335,0$ \\
\hline Área estudio terrestre & 183,0 \\
\hline Área 1ra milla en zona estudio & 253,6 \\
\hline Área 8 millas en zona de estudio & $1.967,0$ \\
\hline $\begin{array}{l}\text { Zona pesca industrial (2013 + Arrastre poliva- } \\
\text { lente) }\end{array}$ & $1.427,0$ \\
\hline Zona pesca artesanal (área marina - 1ra milla) & $3.081,4$ \\
\hline Zona de transporte & $1.060,0$ \\
\hline Camaroneras & 110,6 \\
\hline Zona Navegación Turismo & 279,0 \\
\hline Zona Conservación & 260,7 \\
\hline
\end{tabular}


Iturralde, Vera \& Coronel
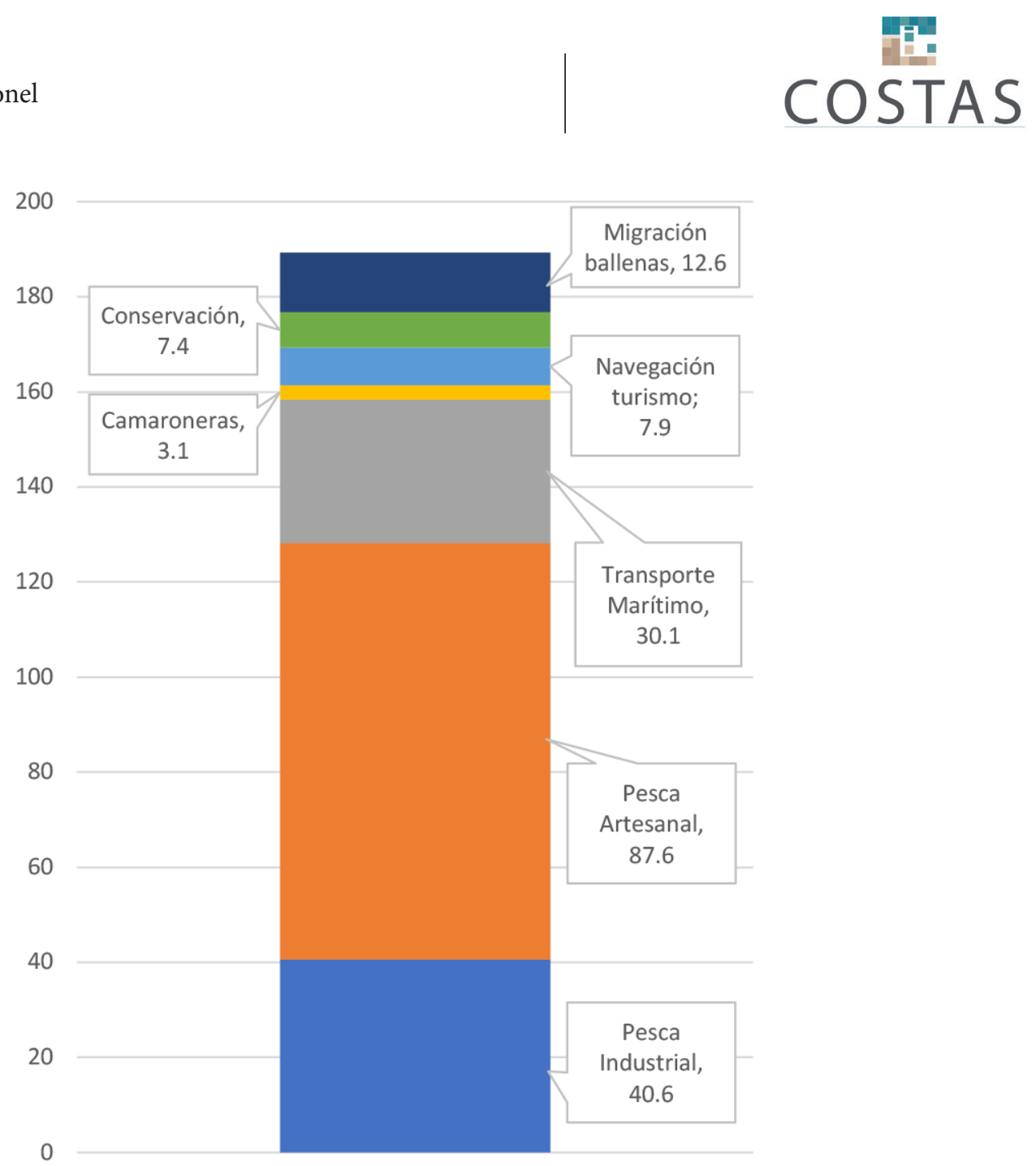

Figura 23. Proporción (porcentaje) del uso del espacio marino en el área de estudio. Fuente: Coronel (2018). Figure 23. Proportion (percentage) of the use of marine space in the study area. Source: Coronel (2018).

\section{Conclusiones}

Por lo expuesto, se concluye que el área Manabí Norte actualmente presta las condiciones para implementar un proceso de ordenamiento marino costero piloto, debido a que hay una buena predisposición de los actores locales y la ventaja que su situación es realmente manejable en consideración con otras regiones del país, lo que nos brinda una excelente oportunidad para lograr resultados tangibles en el corto y mediano plazo que puedan replicarse en otras zonas del país.
En el área de estudio, existen una serie de conflictos, muy similares a los que producen en el resto de la costa ecuatoriana, entre los cuales destacan los conflictos entre los sectores de pesca artesanal e industrial y el escaso ordenamiento de la zona costera, especialmente en las playas. Esto permite identificarla como un emplazamiento adecuado para desarrollar un proyecto piloto de ordenamiento marino costero. 


\section{ris COSTAS}

Se percibe una buena receptividad de parte de las comunidades locales, los pescadores y los gobiernos locales, pero se sienten decepcionados por la escasa implementación de la normativa actual, como por ejemplo las normas pesqueras respetando las 8 millas para la pesca artesanal, a pesar de la tecnología existente (VMS).

Adicionalmente, la falta de implementación a nivel local es una dificultad por lo que es necesario el establecimiento de un órgano que, de forma participativa, defina las metas de desarrollo locales respecto a los temas marinos y costeros; así como la resolución de conflictos y la definición de la ruta a seguir. Este órgano debe tener el respaldo legal y político suficiente para poder lograr sus objetivos.

Las necesidades económicas en una zona que antes de la emergencia sanitaria, generada por la pandemia de COVID-19, ya tenía elevados índices de pobreza y desempleo no debe de ser excusa para la sobreexplotación de los recursos naturales. La falta de planificación conduce a la creación de conflictos entre usuarios de la zona marina y costera; la contaminación; y la pérdida de hábitats, y más bien la situación actual se debe de convertir en la oportunidad para buscar oportunidades de desarrollo de forma armoniosa y equitativa.

El ordenamiento del espacio marino y costero es la metodología adecuada para lograr alcanzar los objetivos de desarrollo sustentable en la zona costera, considerando aspectos de equidad y desarrollo económico y esta área presenta las condiciones adecuadas para implementar este tipo de procesos, pero necesita el apoyo político para lograrlo.

\section{Lecciones aprendidas}

- La autoridad que está impulsando los procesos locales de ordenamiento del espacio marino en base a los lineamientos nacionales es el Ministerio del Ambiente y Agua, con el apoyo de las agencias de cooperación internacional y organi- zaciones no gubernamentales, pero esto limita su implementación cuando se acaba el financiamiento externo y al no tener el apoyo político para continuar con estas iniciativas.

- En base a la información disponible y el conocimiento local y de expertos, el uso de sensores remotos, se puede obtener una muy buena aproximación de los usos actuales del espacio marino y costero y permite identificar los conflictos actuales y potenciales en la zona. El criterio de expertos también ayuda a suplir la falta de información sobre los posibles impactos ambientales de las actividades en el sitio (Elliot et al., 2018)

- La participación ciudadana debe de incluirse desde el principio, incluso desde la definición de los límites del área a intervenir.

- Se han identificado algunos conflictos que se están comenzando a gestar (por ejemplo, acuicultura de agua dulce) y es el momento de enfrentarlos de forma integral antes de que sean irreversibles.

- No se pudo acceder a información detallada sobre las pesquerías artesanales en el área por lo que no se sabe cuál es su estado actual, se debe impulsar la investigación socio pesquera en la zona. Es indispensable, seguir recopilando información, y generar nueva información para el manejo (por ejemplo, stocks pesqueros). Esto debe de ser considerado como un proceso dinámico que se retroalimenta y mejora en calidad con el tiempo.

- Para efectos de mantener actualizado el mapa de actores, se recomienda mantener la participación efectiva de los beneficiarios en el diseño del ordenamiento e implementación mediante la creación de espacios para el dialogo y la resolución de conflictos, así como identificar en el desarrollo de las posibles oportunidades generadas por el proyecto.

- La falta de información científica sólida y arbitrada no debe de ser motivo de retrasar la implementación de procesos de ordenamiento y 
puedan realizarse de forma simultánea siguiendo el principio precautelatorio. En este contexto, es importante realizar un acercamiento con las universidades y ONG para impulsar la generación de información biológica, ecológica, económica y social para el manejo de los recursos costeros.

\section{Agradecimientos}

Estos estudios fueron el resultado del proyecto de Cooperación Triangular entre los países del Ecuador (Ministerio del Ambiente y Agua - MAE), Costa Rica (Sistema de Áreas de Conservación - SINAC) y Alemania (Gesellschaft für Internationale Zusammenarbeit - GIZ). Se transfirieron experiencias, metodologías y lecciones aprendidas del Proyecto "Biodiversidad Costera Marina de Costa Rica - Adaptación al Cambio Climático - SINAC-MINAE-GIZ”, el cual había sido financiado por el Ministerio Federal

\section{Referencias}

Alava JJ, Barragan MJ, Castro C, Carvajal R. 2005a. A note on strandings and entanglements of humpback whales (Megaptera novaeangliae) in Ecuador. Journal of Cetacean Research and Management, 7(2):163-168.

Alava JJ, Jiménez P, Peńafiel M, Aguirre W, Amador P. 2005b. Sea turtle strandings and mortality in Ecuador: 1994-1999. Marine Turtle Newsletter, 108:4-7

Alava JJ, Barragan MJ, Denkinger J. 2012. Assessing the impact of bycatch on Ecuadorian humpback whale breeding stock: a Review with Management Recommendations. Ocean and Coastal Management, 57: 3443

Alava JJ, Lindop A, Jacquet J. 2015. Reconstruction of Marine Fisheries Catches for continental Ecuador, 1950-2010. UBC Fisheries Centre Working Paper \# 2015-34, University of British Columbia, Vancouver, Canada. 25p. [online] < https://open.library. ubc.ca/cIRcle/collections/facultyresearchandpublications/52383/items/1.0074755 >.
- Hay otras iniciativas de conservación en los alrededores como por ejemplos áreas protegidas y corredores de conservación que deben ser involucrados o incluidas en esta iniciativa y, por lo tanto, no pueden ser dejadas de lado.

de Medio Ambiente, Protección de la Naturaleza y Seguridad Nuclear (BMU) en el marco su Iniciativa Internacional de la Protección del Clima "IKI". El proyecto de Cooperación Triangular fue financiado por el Ministerio de Cooperación Económica de la República de Alemania (BMZ), el Sistema de Áreas de Conservación (SINAC) de Costa Rica y el Ministerio de Ambiente (MAE) de la República del Ecuador. Muy agradecido por los comentarios y sugerencias de JJA y JCP y dos revisores anonimos.

Alava JJ, Tatar B, Barragán MJ, Castro C, Rosero P, Denkinger J, Jiménez PJ, Carvajal R, Samaniego J. 2019. Mitigating Cetacean Bycatch in Coastal Ecuador: Governance Challenges for Small-scale Fisheries. Marine Policy, 110: 102769 DOI 10.1016/j. marpol.2017.05.025 https://doi.org/10.1016/j.marpol.2017.05.025

Alcívar LE, Guevara JL, Peñafiel SS. 2011. Caracterización y propuesta técnica de la acuicultura en el sector de Jama provincia de Manabí [disertación]. Facultad de Ingeniería Marítima y Ciencias del Mar. Escuela Politécnica del Litoral [ESPOL].

Ayón H. 1988. Grandes rasgos geomorfológicos de la costa ecuatoriana. PMRC-Proyecto de Manejo de Recursos Costeros.

Bioelite. 2017. Análisis comparativo de la diversidad, abundancia y distribución de las especies registradas en seis áreas marinas costeras protegidas y cuatro de posible expansión. Informe de consultoría para 


\section{rin \\ COSTAS}

el Ministerio del Ambiente. Quinto producto del contrato CFC-001-2015. Bioelite. Febrero de 2016. Guayaquil, Ecuador. Proyecto de Conservación de la Biodiversidad. MAE/ BID /GEF.

Boothroyd JC, Ayón H, Robadue D, Vásconez J, Noboa R. 1994. Características de la línea costera del Ecuador y recomendaciones para su manejo. Coastal Resources Center.

[CEPAL] Comisión Económica para América Latina y el Caribe. 2003. Bases conceptuales para el ciclo de cursos sobre gerencia de proyectos y programas. Instituto Latinoamericano y del Caribe de Planificación Económica y Social - ILPES. Santiago de Chile, Chile.

Chavarría JX. 2015. Macro y microzonificación del mar ecuatoriano para el desarrollo de la maricultura de pargo (Lutjanus guttatus) y huayaipe (Seriola rivoliana) usando criterios de sostenibilidad. Tesis para obtener el título de Doctor en Ingeniería y Ciencias Ambientales. Universidad Nacional Agraria La Molina. Escuela de Posgrado.

Cifuentes M, Izurieta A, de Faria HH. 2000. Medición de la efectividad del manejo de áreas protegidas. FOREST INNOVATIONS PROJECT. Serie Técnica \#2. WWF, IUCN and GTZ, Turrialba, Costa Rica.

Collie JS, Beck MW, Craig B, Essington TE, Fluharty D, Rice J, Sanchirico JN. 2013. Marine spatial planning in practice. Estuarine, Coastal and Shelf Science, 117: $1-11$.

Coronel J. 2018. Estudio de prefactibilidad para el ordenamiento espacial marino (OEM) con enfoque ecosistémico desde el estuario del Río Muisne, hasta el estuario del Río Chone, - Provincia de Esmeraldas y Manabí: Componente Cartográfico. Documento interno. proyecto de Cooperación Triangular entre los países del Ecuador (Ministerio Ambiente - MAE), Costa Rica (Sistema de Áreas de Conservación SINAC) y Alemania (Gesellschaft für Internationale Zusammenarbeit - GIZ).

Ehler C, Douvere F. 2009. Planificación espacial marina: una guía paso a paso hacia la Gestión Eco sistémica. Comisión Oceanográfica Intergubernamental y el Programa del Hombre y la Biosfera. COI manuales y guías n. ${ }^{\circ} 53$.

Ehler C, Douvere, F. 2010. An international perspective on marine spatial planning initiatives. Environments: a journal of interdisciplinary studies, 37(3).
Revista Costas, Vol. Esp. 2, 2021

Elliott M, Boyes SJ, Barnard S, Borja Á. 2018. Using best expert judgement to harmonize marine environmental status assessment and maritime spatial planning. Marine pollution bulletin, 133: 367-377.

El Diario. 2011, 2 de julio. Barcos chinchorreros causan malestar. www.eldiario.ec/noticias-manabi-ecuador/196984-barcos-chinchorreros-causan-malestar/

El Productor. 2020, 24 de agosto. Pescadores artesanales piden reforma a ley que regula actividad. elproductor.com/ecuador-pescadores-artesanales-piden-reforma-a-ley-que-regula-actividad/

El Telégrafo. 2014, 8 de febrero. Pesca chinchorrera genera \$ 240 millones al año. < www.eltelegrafo.com. ec/noticias/economia/8/pesca-chinchorrera-genera-240-millones-al-ano $\geq$.

Frazão Santos C, Agardy T, Andrade F, Crowder LB, Ehler CN, Orbach MK. 2018. Major challenges in developing marine spatial planning. Marine Policy, In press. https://doi.org/10.1016/j.marpol.2018.08.032.

Frazão Santos C, Ehler CN, Agardy T, Andrade F, Orbach MK, Crowder LB. 2019. Marine spatial planning. In World seas: an environmental evaluation (pp. 571592). Academic Press.

Gobierno Autónomo Descentralizado Parroquial de Cojimíes. 2015. Plan de Desarrollo y Ordenamiento Territorial. [online] < http://gadcojimies.gob.ec/ manabi/wp-content/uploads/2015/01/PDOTCOJIMIES.pdf $>$.

Gobierno Autónomo Descentralizado Cantonal de Jama. 2015. Plan de Desarrollo y Ordenamiento Territorial. [online] < http://app.sni.gob.ec/sni-link/sni/ PORTAL_SNI/data_sigad_plus/sigadplusdocumentofinal/1360020740001_PDyOT\%20Jama\%20integral_19-04-2015_14-44-50.pdf >.

Gobierno Autónomo Descentralizado Cantonal de Pedernales. 2015. Plan de Desarrollo y Ordenamiento Territorial. [online] < http://app.sni.gob.ec/sni-link/sni/ PORTAL_SNI/data_sigad_plus/sigadplusdiagnostico/DIAGNOSTICO $\% 20$ ESTRATEGICO $\% 20$ PEDERNALES\%202014_14-11-2014.pdf $>$.

Gobierno Autónomo Descentralizado Cantonal de San Vicente. 2015. Plan de Desarrollo y Ordenamiento Territorial. [online] < https://drive.google.com/ file/d/1WnUorl1ZvVJHv0zfsUUc2AnTTi4tlDEo/ view $>$.

Gobierno del Ecuador. 2008. Constitución de la República del Ecuador. Asamblea Constituyente. Publicada 
en el Registro Oficial No. 44920 de octubre de 2008. [online] < https://www.asambleanacional.gob.ec/ sites/default/files/documents/old/constitucion_de_ bolsillo.pdf $>$.

González N, Prado M, Castro R, Solano F, Jurado V, Peña M. 2008. Análisis de la pesquería de peces pelágicos pequeños en el ecuador (1981-2007). Instituto $\mathrm{Na}$ cional de Pesca. Documento interno.

Greenhill L. 2018. Challenges and opportunities for governance in marine spatial planning. In Offshore Energy and Marine Spatial Planning (pp. 56-73). Routledge.

[INEC] Instituto Ecuatoriano de Estadísticas y Censo. 2010a. Proyección de la población ecuatoriana, por años calendario, según cantones 2010-2020. [online] < https://www.ecuadorencifras.gob.ec/proyecciones-poblacionales/ $>$.

[INEC] Instituto Ecuatoriano de Estadísticas y Censo. 2010b. Censo de Población y Vivienda 2010. Pobreza por Necesidades Básicas Insatisfechas - NBI. [online] < http://www.ecuadorencifras.gob.ec/documentos/ web-inec/POBREZA/NBI/NBI-FUENTE-CPV/ Tabulados_pobreza_por_NBI.xlsx $>$.

[INEC] Instituto Ecuatoriano de Estadísticas y Censo. 2018. Encuesta Nacional de Empleo, Desempleo y Subempleo (ENEMDU). [online] < https://www. ecuadorencifras.gob.ec/empleo-septiembre-2020/ >.

[INP] Instituto Nacional de Pesca. 2013. Puertos, caletas y asentamientos pesqueros artesanales del Ecuador. Boletín Especial 04 (01).

[INP] Instituto Nacional de Pesca. 2016. Determinación del estado actual de la biomasa del recurso camarón rojo y café, mediante prospección biológica pesquera, fuera de las 8 (ocho) millas náuticas del perfil costero ecuatoriano (agosto 2015 - agosto 2016). Informe Técnico.

[INP] Instituto Nacional de Pesca. 2018. Desembarques mensuales de peces pelágicos pequeños - periodo 2004 - 2017. Informe Técnico.

Iturralde G. 2018. Estudio de prefactibilidad para el ordenamiento espacial marino (OEM) con enfoque ecosistémico desde el estuario del Río Muisne, hasta el estuario del Río Chone, - Provincia de Esmeraldas y Manabí. Informe de Consultoría presentado al proyecto de Cooperación Triangular entre los países del Ecuador (Ministerio Ambiente - MAE), Costa
Rica (Sistema de Áreas de Conservación - SINAC) y Alemania (Gesellschaft für Internationale Zusammenarbeit - GIZ).

La Hora. 20101 de octubre. Pesqueros respaldan amparo constitucional. [online] < lahora.com.ec/noticia/1101026428/pesqueros-respaldan-amparo-constitucional $>$.

Mamani C. 2013. Más allá del horizonte: reconfiguración del territorio de la pesca artesanal a partir de la ampliación del espacio de pesca: investigación con los pescadores de la comunidad El Matal, del Cantón Jama, de la Provincia de Manabí, Ecuador. Master's thesis, Quito: FLACSO Sede Ecuador.

Martínez-Ortiz J, Aires-da-Silva AM, Lennert-Cody CE, Maunder MN. 2015. The Ecuadorian Artisanal Fishery for Large Pelagics: Species Composition and Spatio-Temporal Dynamics. PLoS ONE, 10(8): e0135136. doi:10.1371/journal.pone.0135136

Marviva. 2012. Guía Metodológica para el ordenamiento espacial marino en Costa Rica. Proyecto "BID-SINAC-MarViva, Manejo Integrado de los Recursos Marino-Costeros en la Provincia de Puntarenas" financiado por el Fondo para el Medio Ambiente Mundial (FMAM) a través del Banco Interamericano de Desarrollo (BID) y ejecutado mediante la consultoría CR-X1004 de MarViva.

Mestanza-Ramón C, Capa MS, Saavedra HF, Paredes JR. 2019. Integrated Coastal Zone Management in Continental Ecuador and Galapagos Islands: Challenges and Opportunities in a Changing Tourism and Economic Context. Sustainability, 11(22): 6386.

[Mintur] Ministerio de Turismo del Ecuador. 2004. Inventario de atractivos turísticos del Ecuador. Informe interno.

[Mintur] Ministerio de Turismo del Ecuador. 2018. Geoportal de Visitas Internas Turísticas (2017). Coordinación General de Estadística e Investigación MINTUR. [online] < https://servicios.turis mo.gob. ec/index.php/turismo-cifras/2018-09-19-17-01-51/ movimientos-internos-geovit $>$.

[MPCEIP] Ministerio de la Producción, Comercio Exterior, Inversiones y Pesca. 2019. Periodo de Vedas Ecuador 2019. [online] < https://www.produccion. gob.ec/wp-content/uploads/2019/09/Calendario-Vedas-Ecuador_final_OUTLINE_compressed.pdf >. 


\section{監 \\ COSTAS}

MSPGlobal 2030. 2020. La PEM en el Mundo: Américas. [online] < http://www.mspglobal2030.org/es/ msp-roadmap/la-pem-en-el-mundo/americas/; 15 december $2020>$.

Ormaza F, Anastacio J, Velasco M. 2018. Análisis de Causa Raíz para la pesquería de Peces Pelágicos Pequeños en Ecuador. Informe de Consultoría. Proyecto Cadenas Mundiales Sostenibles. Ministerio de Acuicultura y Pesca/ Sustainable Fisheries Partnership/ PNUD/ GEF.

Paguay J. 2014. 16A/TUR parte 2.- El Turismo Post 16 de abril. Blog Turismo ConCiencia. https://jorgepaguay. wordpress.com/

[PMRC] Programa de Manejo de Recursos Costeros. 1993. Plan de Manejo de la ZEM Bahía- San Vicente - Canoa.

[PMRC] Programa de Manejo de Recursos Costeros. 2000. Macrozonificacion de la zona costera continental del Ecuador.

Quelal PA. (2013). Representaciones de aves en la iconografía de la cultura Jama Coaque [disertación]. Escuela de Antropología, Pontificia Universidad Católica del Ecuador [PUCE].

Santos AP, Carofilis JF, Vargas VH. 2011. Caracterización y propuesta técnica de la acuacultura en el sector de Cojimíes, provincia de Manabí [disertación]. Facultad de Ingeniería Marítima y Ciencias del Mar. Escuela Politécnica del Litoral [ESPOL].

Schmidtbauer J (ed.). 2017. The Ecosystem Approach in Maritime Spatial Planning: a checklist toolbox. the Baltic SCOPE Project. European Maritime and Fisheries Fund. European Union.

[SRP] Subsecretaría de Recursos Pesqueros. 2020. Establecer el periodo de veda del ańo dos mil veinte para el recurso merluza (Merluccius gayi). Acuerdo Nro. MPCEIP-SRP-2020-0053-A. Miércoles 27 de mayo de 2020 Registro Oficial No 211.

[Senplades] Secretaría Nacional de Planificación y Desarrollo. 2017. Plan Nacional de Desarrollo 2017-2021. Toda una Vida. Quito- Ecuador.

[Senplades] Secretaría Nacional de Planificación y Desarrollo. 2018. Plan de Ordenamiento Marino y Costero (POEMC).

[Setemar] Secretaría Técnica del Mar. 2014. Políticas Públicas Costeras y Oceánicas: Diagnóstico y propuesta de implementación. Biotica Cía. Ltda. Editorial El Telégrafo.
Revista Costas, Vol. Esp. 2, 2021

Stratega. 2010. Consultoría para la elaboración de estudios básicos y de factibilidad para la implementación de proyectos de maricultura en 10 áreas del mar costero ecuatoriano para la diversificación productiva del sector pesquero artesanal. Informe final presentado a la Subsecretaría de Recursos Pesqueros. Manuscrito inédito.

[Subacua] Subsecretaría de Acuacultura, Ministerio de Acuacultura y Pesca. 2018. Concesiones Maricultura. En base de datos Senplades. Plan de Ordenamiento Marino y Costero.

UN Environment. 2018. Conceptual guidelines for the application of Marine Spatial Planning and Integrated Coastal Zone Management approaches to support the achievement of Sustainable Development Goal Targets 14.1 and 14.2. UN Regional Seas Reports and Studies No. 207. 58pp

[Unesco/IOC] United Nations Educational, Scientific and Cultural Organization/Comisión Oceanográfica Intergubernamental. La PEM en el mundo. [online] $<$ http://mspes.ioc-unesco.org/aplicaciones/vision-general $/ \geq, 12 / 2020$.

Veidemane K, Ruskule A, Sprukta S. 2017. Development of a Maritime Spatial Plan: The Latvian Recipe. BalticScope.

Vera M. 2018. Estudio de prefactibilidad para el ordenamiento espacial marino (OEM) con enfoque ecosistémico desde el estuario del Río Muisne, hasta el estuario del Río Chone, - Provincia de Esmeraldas y Manabí: Componente Social. Documento interno. proyecto de Cooperación Triangular entre los países del Ecuador (Ministerio Ambiente - MAE), Costa Rica (Sistema de Áreas de Conservación - SINAC) y Alemania (Gesellschaft für Internationale Zusammenarbeit - GIZ).

Villegas T, Navarrete R, Arriaga L, Coello S. 2005. Evaluación de factibilidad de una red de áreas costeras y marinas protegidas en Ecuador. Informe de consultoría para el Banco Interamericano de Desarrollo y Ministerio del Ambiente: 143pp.

[VMAP] Viceministerio de Acuacultura y Pesca. 2014. Situación Actual de la Pesca en el Ecuador. Presentación. [online] < https://www.academia. edu/23874414/CENSO_PESQUERO_FASE_ COMPLEMENTARIA_SITUACION_ACTUAL_ DE_LA_PESCA_EN_ECUADOR $\geq$. 
Iturralde, Vera \& Coronel

World Ocean Council. 2014. International Ocean Governance: Marine Planning Brief.

[WWF] World Wide Fund for Nature. 2015. Reviving the Ocean Economy: the case for action - 2015. WWF International, Gland, Switzerland., Geneva, 60 pp. [online] < https://wwfeu.awsassets.panda.org/downloads/reviving_ocean_economy_report_hi_res.pdf $>$.

[WWF] World Wide Fund for Nature. 2018. Taller de trabajo: Planificación y Ordenamiento Espacial Marino y Costero en el Ecuador con énfasis en Áreas Protegidas y corredores de conservación. Proyecto: Fortalecimiento de áreas protegidas y corredores de conservación marinos y costeros para proteger la megafauna marina clave y asegurar formas de vida sostenibles (IKU). Elaborado para la WWF y el Ministerio del Ambiente del Ecuador. 


\section{$\cos$ \\ COSTAS}

Revista Costas, Vol. Esp. 2, 2021

$>4064$ 